\title{
Article \\ Phytochemical Profile and Microbiological Activity of Some Plants Belonging to the Fabaceae Family
}

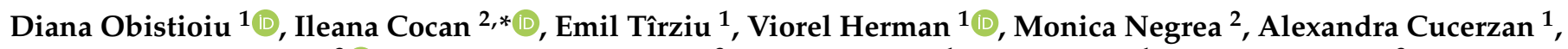 \\ Alina-Georgeta Neacsu ${ }^{3}{ }^{-}$, Antoanela Lena Cozma ${ }^{3}$, Ileana Nichita ${ }^{1}$, Anca Hulea ${ }^{1}$, Isidora Radulov ${ }^{3}$ and \\ Ersilia Alexa ${ }^{2}$ (1)
}

1 Faculty of Veterinary Medicine, Banat University of Agricultural Sciences and Veterinary Medicine "King Michael I of Romania" Timisoara, Calea Aradului No. 119, 300645 Timisoara, Romania; dianaobistioiu@usab-tm.ro (D.O.); emiltirziu@usab-tm.ro (E.T.); viorelherman@usab-tm.ro (V.H.); alexandracucerzan@usab-tm.ro (A.C.); ileananichita@usab-tm.ro (I.N.); anca.hulea@usab-tm.ro (A.H.)

2 Faculty of Food Engineering, Banat University of Agricultural Sciences and Veterinary Medicine "King Michael I of Romania" Timisoara, Calea Aradului No. 119, 300645 Timisoara, Romania; monicanegrea@usab-tm.ro (M.N.); ersiliaalexa@usab-tm.ro (E.A.)

3 Faculty of Agriculture, Banat University of Agricultural Sciences and Veterinary Medicine "King Michael I of Romania" Timisoara, Calea Aradului No. 119, 300645 Timisoara, Romania; alinaneacsu@usab-tm.ro (A.-G.N.); cozma@usab-tm.ro (A.L.C.); isidora_radulov@usab-tm.ro (I.R.)

* Correspondence: ileanacocan@usab-tm.ro

Citation: Obistioiu, D.; Cocan, I.; Tîrziu, E.; Herman, V.; Negrea, M.; Cucerzan, A.; Neacsu, A.-G.; Cozma, A.L.; Nichita, I.; Hulea, A.; et al. Phytochemical Profile and Microbiological Activity of Some Plants Belonging to the Fabaceae Family. Antibiotics 2021, 10, 662. https://doi.org/10.3390/ antibiotics 10060662

Academic Editors: Gianna Tempera, Carlo Genovese and Antonia Nostro

Received: 14 April 2021

Accepted: 28 May 2021

Published: 1 June 2021

Publisher's Note: MDPI stays neutral with regard to jurisdictional claims in published maps and institutional affiliations.

Copyright: (c) 2021 by the authors. Licensee MDPI, Basel, Switzerland. This article is an open access article distributed under the terms and conditions of the Creative Commons Attribution (CC BY) license (https:// creativecommons.org/licenses/by/ $4.0 /)$.

\begin{abstract}
This study aimed to investigate the chemical composition and the activity against Staphylococcus aureus (S. aureus) (ATCC 25923), Streptococcus pyogenes (S. pyogenes) (ATCC 19615), Escherichia coli (E. coli) (ATCC 25922), Pseudomonas aeruginosa (P. aeruginosa) (ATCC 27853), Shigella flexneri (S. flexneri) (ATCC 12022), Salmonella typhimurium (S. typhimurium) (ATCC 14028), Haemophillus influenzae (H. influenza) type B (ATCC 10211) and two fungal strains: Candida albicans (C. albicans) (ATCC 10231) and Candida parapsilopsis (C. parapsilopsis) (ATCC 22019) of the extracts obtained from Melilotus officinalis (MO), Coronilla varia (CV); Ononis spinosa (OS) and Robinia pseudoacacia (RP) (Fabaceae), and to identify the chemical compounds responsible for the antimicrobial effect against the tested strains. The extracts were obtained by conventional hydroalcoholic extraction and analyzed in terms of total polyphenols using the spectrophotometric method and by liquid chromatography (LC). The results have shown that the highest polyphenols content was recorded in the RP sample (16.21 mg gallic acid equivalent GAE/g), followed by the CV (15.06 mg GAE/g), the OS (13.17 mg GAE/g), the lowest value being recorded for the MO sample (11.94 mg GAE/g). The antimicrobial testing of plant extracts was carried out using the microdilution method. The most sensitive strains identified were: E. coli, S. typhimurium, P. aeruginosa and S. pyogenes, while protocatechuic acid, gallic acid, caffeic acid, quercetin, rutin, and kaempferol were identified as the chemical compounds responsible for the antibacterial effect. The analysis of the correlation between the chemical composition and the antimicrobial effect proved a moderate $(\mathrm{r}>0.5)$ positive correlation between rosmarinic acid and S. pyogenes $(\mathrm{r}=0.526)$, rosmarinic acid and S. typhimurium $(\mathrm{r}=0.568)$, quercetin and C. albicans $(\mathrm{r}=0.553)$, quercetin and S. pyogenes $(\mathrm{r}=0.605)$. Therefore, it suggested possible antimicrobial activity generated by these chemical components. The results recommend the Fabaceae plants as promising candidates for further research to develop novel natural antimicrobial drugs.
\end{abstract}

Keywords: Melilotus officinalis; Coronilla varia; Ononis spinosa; Robinia pseudoacacia; phytochemical profile; microbiological activity

\section{Introduction}

Despite the availability of several antibiotics and antimycotics, the treatment of patients, especially the immunocompromised ones, is still limited because of low drug potency. The emergence of resistant strains and diseases due to certain free radicals, mainly 
oxygen reactive species also makes treatment challenging. Together with the undesirable side effects of certain medicines, this situation is a serious medical problem, making it essential to find new sources of antibacterial and antifungal agents.

Based on the reports received through the European Antimicrobial Resistance Surveillance Network (EARS-Net), the WHO reports alarming growth rates of pathogenic microorganisms that have developed multiple resistances to common drugs [1]. Unfortunately, the pharmaceutical industry does not have the required rate of production of synthetic, allopathic drugs to cover the development of these multi-resistant organisms. This study is intended to obtain untested, natural compounds existing in the spontaneous flora, which have antimicrobial activity.

Our research investigates the chemical composition, antimicrobial, and phytochemical activity of four extracts obtained from the Fabaceae family flowers, which grow wild in Western Romania. The four selected plants were: Melilotus officinalis (MO) (Melilot, Sweet clover); Coronilla varia (CV) (Scorpion vetch); Ononis spinosa (OS) (Spiny restharrow), and Robinia pseudoacacia (RP) (Black locust).

The Fabaceae, or Leguminosae, is one of the three largest flowering plants, exceeded only by the Compositae and Orchidaceae, with an estimated $\sim 750$ genera [2]. From an economic point of view, the Fabaceae family is second only to Gramineae, including many economically and medicinally important flowering plants.

The main criteria for their selection was their abundance in the wild flora in Western Romania, with all four plants being native or naturalized in our country but need further research [3]. The main activities of the four plants studied, and their references are presented in Table 1.

Table 1. The main activities of the investigated plants.

\begin{tabular}{|c|c|c|c|}
\hline Plant & Popular Name & Biological Activity & References \\
\hline \multirow[t]{3}{*}{ Melilotus officinalis (MO) } & \multirow[t]{3}{*}{ Melilot, sweet clover } & $\begin{array}{l}\text { Used traditionally for the treatment of insect bite, } \\
\text { circulatory disturbance in minor veins, liver } \\
\text { disorders, hypertension, arthritis, hemorrhoids, and } \\
\text { bronchitis }\end{array}$ & [4-6] \\
\hline & & Antimicrobial effects: & {$[7,8]$} \\
\hline & & $\begin{array}{l}\text { Greater effect on Gram-positive bacteria than on the } \\
\text { Gram-negative bacteria }\end{array}$ & [9] \\
\hline \multirow[b]{2}{*}{ Coronilla varia (CV) } & \multirow[b]{2}{*}{ Crown vetch } & $\begin{array}{l}\text { Cardiac, diuretic, purgative, diuretic heart tonic, } \\
\text { antibacterial, and anticancer activities }\end{array}$ & [10-12] \\
\hline & & $\begin{array}{l}\text { CV methanolic extract exhibited antibacterial } \\
\text { activity against S. pyogenes (ATCC 19615), S. aureus } \\
\text { (ATCC 25923), S. epidermidis (ATCC 12228), P. } \\
\text { aeruginosa (ATCC 27853), K. pneumoniae (ATCC } \\
\text { 13883), and E. coli (ATCC 25922) through the disc } \\
\text { diffusion assay }\end{array}$ & [13] \\
\hline \multirow{2}{*}{ Ononis spinosa (OS) } & \multirow{2}{*}{ Spiny restharrow } & $\begin{array}{l}\text { Used for the urinary tract, kidney stones, } \\
\text { inflammatory diseases, wound healing, skin } \\
\text { disorders and/or infections, antibacterial, antifungal, } \\
\text { anti-inflammatory, and analgesic effects. }\end{array}$ & {$[14,15]$} \\
\hline & & $\begin{array}{l}\text { Aqueous extracts active against S. Pyogenes and } \\
\text { Gram-positive microorganisms as E. Coli, P. } \\
\text { Aeruginosa, S. Typhimurium, S. Aureus, and C. } \\
\text { Albicans }\end{array}$ & {$[16,17]$} \\
\hline Robinia pseudoacacia (RP) & Black locust & $\begin{array}{l}\text { Antacid, antibacterial, antifungal, purgative effects } \\
\text { and acts as an emmenagogue }\end{array}$ & [18] \\
\hline
\end{tabular}


According to [19], M. officinalis exerted antimicrobial effects when containing flavonoids and various phenolic compounds, melilotin, volatile oil, mucilage, tannin, fatty acid, triterpenes, coumarin, bishydroxycoumarin, choline, and glycosides.

Coronilla varia (CV), or Crown vetch is a perennial invasive Fabaceae plant, an important source of phytochemicals such as polyphenols, including gallic acid and resveratrol [15].

Robinia pseudoacacia (RP) is one of the most well spread and naturated exotic plants [3]. The literature studies present the chemical composition of R. pseudoacacia, as flavonoids including robinin (kaempferol-3-O-ramnozilgalactozil-7-ramnozide), acacetin-7-O-rutoside, apigenin, diosmetin, luteolin, secundiflorol, mucronulatol, isomucronulatol, and isovestitol that are of pharmaceutical importance [20-23].

Many pathological ailments, including inflammatory diseases and infectious or microbial diseases, are caused by free radicals and their destruction [24,25]. The formation and activation of some reactive oxygen species (ROS) are some of the potentially damaging effects of oxygen. Many such species are represented by free radicals resulting from normal metabolic processes in the human body or from external sources [25].

However, the damaging effects of free radicals can be diminished by natural antioxidants, with the highest availability in plants. There being studies proving the extraordinary ability to collect radicals by various natural compounds extracted from plants.

Previous studies have focused on analyzing different plant biological activities to discover new antimicrobial agents that target free radicals. Several studies have demonstrated the antioxidant or radical properties of herbal extracts and the mechanism of action of these compounds $[26,27]$.

It was determined that the antioxidant properties of plant extracts are attributed to their richness in isoprenoid quinones, which act as chain terminators of free radicals and as chelators ROS [25]. In addition, Gordon (1990) [28] indicated that the phenolic compounds existing in the commercial extracts act as primary antioxidants when reacting with the lipid and hydroxyl radicals to turn them into stable products. These compounds react with present metal ions, so chelates are formed; they consequently react with peroxide radicals and, in that way, stabilize these free radicals [25].

Given this, the purpose of this study was to determine which of the selected plants have antimicrobial activity and to identify the chemical components responsible for these properties.

The experimental part involved: (i) obtaining $\mathrm{MO}, \mathrm{CV}$, OS, and RP hydroalcoholic extracts; (ii) analyzing the total polyphenols content and polyphenolic profile of $\mathrm{MO}, \mathrm{CV}, \mathrm{OS}$, and RP extracts using the LC methodology; (iii) testing the in vitro antimicrobial effect of extracts and individual polyphenols; (iv) the correlation between the analyzed parameters.

To the best of our knowledge, the local wild plant species selected for this study are being screened for the first time regarding their chemical composition and their antimicrobial effects linked to their specific composition.

\section{Results}

\subsection{Chemical Composition of Extracts}

Figure 1 presents the total polyphenols content (TPC) expressed as mg gallic acid equivalent GAE/g sample of the analyzed hydroalcoholic extracts detected using the UV spectrophotometric method. In contrast, Table 2 presents the individual profile of polyphenols identified and quantified using high-performance liquid chromatography (HPLC). 


\section{Total polyphenols content}

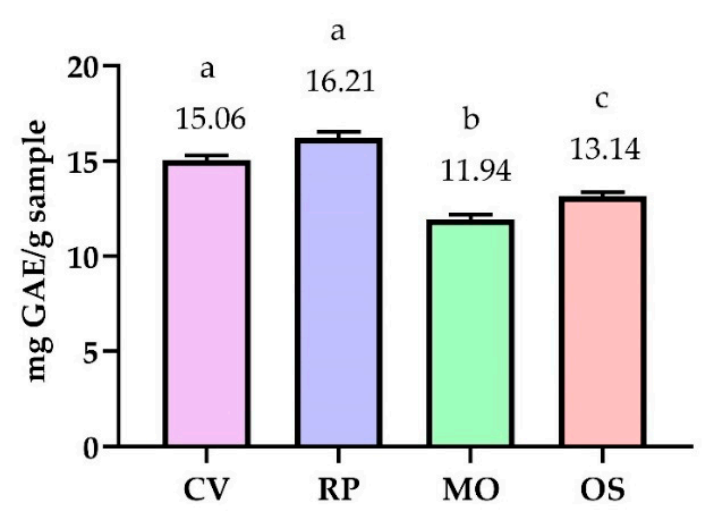

Figure 1. Content of total polyphenols in the studied samples. Mean values are expressed as mg gallic acid equivalent GAE/g sample. The error bars indicate standard deviation. Different letters among samples indicate significant differences $(p<0.05)$ among values according to the $t$-test.

Table 2. The individual profile of polyphenols detected using the LC method $\left(\mathrm{mg}^{\mathrm{g}} \mathrm{g}^{-1}\right)$.

\begin{tabular}{cccccc}
\hline Compound & Retention Time (min) & RP & MO & CV & OS \\
\hline Gallic acid & 4.8 & $0.693 \pm 0.011^{\mathrm{a}}$ & nd & $0.249 \pm 0.006^{\mathrm{b}}$ & $0.007 \pm 0.0001^{\mathrm{c}}$ \\
\hline Protocatechuic acid & 10.8 & $0.701 \pm 0.012^{\mathrm{a}}$ & $0.696 \pm 0.007^{\mathrm{a}}$ & $0.155 \pm 0.006^{\mathrm{b}}$ & $0.011 \pm 0.0003^{\mathrm{c}}$ \\
\hline Caffeic acid & 21.9 & $0.567 \pm 0.008^{\mathrm{a}}$ & $2.441 \pm 0.03^{\mathrm{b}}$ & $0.594 \pm 0.008^{\mathrm{a}}$ & $0.668 \pm 0.013^{\mathrm{c}}$ \\
\hline Epicatechin & 22.7 & $17.002 \pm 0.181^{\mathrm{a}}$ & $65.879 \pm 0.424^{\mathrm{b}}$ & $2.219 \pm 0.025^{\mathrm{c}}$ & $\mathrm{nd}^{\mathrm{n}}$ \\
\hline Coumaric acid & 24.4 & $0.179 \pm 0.004^{\mathrm{a}}$ & $0.999 \pm 0.014^{\mathrm{b}}$ & $0.104 \pm 0.002^{\mathrm{c}}$ & $0.043 \pm 0.001^{\mathrm{d}}$ \\
\hline Ferulic Acid & 24.7 & $\mathrm{nd}$ & $\mathrm{nd}$ & $\mathrm{nd}$ & $0.073 \pm 2.76$ \\
\hline Rutin & 25.7 & $35.257 \pm 2.84^{\mathrm{a}}$ & $7.865 \pm 0.71^{\mathrm{b}}$ & $2.779 \pm 44.42^{\mathrm{c}}$ & $2.156 \pm 60.88^{\mathrm{d}}$ \\
\hline Rosmarinic acid & 28.8 & $4.430 \pm 0.43^{\mathrm{a}}$ & $0.640 \pm 21.12^{\mathrm{b}}$ & $2.051 \pm 38.98^{\mathrm{c}}$ & $4.391 \pm 115.79^{\mathrm{a}}$ \\
\hline Resveratrol & 31.9 & $2.176 \pm 12.73^{\mathrm{a}}$ & $1.518 \pm 27.54^{\mathrm{b}}$ & $1.256 \pm 29.50^{\mathrm{c}}$ & $1.107 \pm 21.24^{\mathrm{d}}$ \\
\hline Quercetin & 32.1 & $1.786 \pm 14.14^{\mathrm{a}}$ & $\mathrm{nd}$ & $0.536 \pm 5.50^{\mathrm{b}}$ & $2.838 \pm 50.54^{\mathrm{c}}$ \\
\hline Kaempferol & 34.9 & $0.669 \pm 7.07^{\mathrm{a}}$ & $1.114 \pm 199.46^{\mathrm{b}}$ & $1.878 \pm 37.9^{\mathrm{c}}$ & $4.861 \pm 54.29^{\mathrm{d}}$ \\
\hline
\end{tabular}

The values are expressed as mean values \pm standard deviations of all measurements. ${ }^{\text {a-d }} t$-test was used to compare the means differences registered among samples; data within the same row sharing different superscripts are significantly different $(p<0.05)$; data within the same row sharing the same superscripts are not significantly different $(p>0.05)$; nd-not detected.

The values for total polyphenols vary within minimal limits. From the data presented, it can be seen that the highest value was recorded in the RP alcoholic extract (16.21 mg GAE/g), followed by CV (15.06 mg GAE/g), OS (13.17 mg GAE/g), and the lowest value was recorded in the $\mathrm{MO}(11.94 \mathrm{mg} \mathrm{GAE} / \mathrm{g})$.

The four investigated Fabaceae species revealed distinct chemical patterns (Table 2). In the $\mathrm{MO}$ alcoholic extract, the main components were: epicatechin $\left(65.879 \mathrm{mg} \cdot \mathrm{g}^{-1}\right)$, kaempferol $\left(1.114 \mathrm{mg} \cdot \mathrm{g}^{-1}\right)$, rutin $\left(7.865 \mathrm{mg} \cdot \mathrm{g}^{-1}\right)$, and caffeic acid $\left(2.441 \mathrm{mg} \cdot \mathrm{g}^{-1}\right)$. Smaller quantities of protocatechuic acid $\left(0.696 \mathrm{mg} \cdot \mathrm{g}^{-1}\right)$, coumaric acid $\left(0.999 \mathrm{mg} \cdot \mathrm{g}^{-1}\right)$, resveratrol $\left(1.518 \mathrm{mg} \cdot \mathrm{g}^{-1}\right)$, and rosmarinic acid $\left(0.64 \mathrm{mg} \cdot \mathrm{g}^{-1}\right)$ were also detected.

Our data showed that in case of the RP alcoholic extract, the main polyphenolic components were rutin $\left(35.257 \mathrm{mg} \cdot \mathrm{g}^{-1}\right)$, epicatechin $\left(17 \mathrm{mg} \cdot \mathrm{g}^{-1}\right)$, rosmarinic acid $\left(4.439 \mathrm{mg} \cdot \mathrm{g}^{-1}\right)$, and resveratrol $\left(2.175 \mathrm{mg} \cdot \mathrm{g}^{-1}\right)$. Other compounds found in minority were gallic acid $\left(0.693 \mathrm{mg} \cdot \mathrm{g}^{-1}\right)$, quercetin $\left(1.786 \mathrm{mg} \cdot \mathrm{g}^{-1}\right)$, protocatechuic acid $\left(0.701 \mathrm{mg} \cdot \mathrm{g}^{-1}\right)$, caffeic acid $\left(0.567 \mathrm{mg} \cdot \mathrm{g}^{-1}\right)$, and kaempferol $\left(0.669 \mathrm{mg} \cdot \mathrm{g}^{-1}\right)$.

The CV extract presented as primary polyphenolic components the following: rutin $\left(2.779 \mathrm{mg} \cdot \mathrm{g}^{-1}\right)$, epicatechin $\left(2.219 \mathrm{mg} \cdot \mathrm{g}^{-1}\right)$, rosmarinic acid $\left(2.051 \mathrm{mg} \cdot \mathrm{g}^{-1}\right)$, kaempferol 
$\left(1.878 \mathrm{mg} \cdot \mathrm{g}^{-1}\right)$, gallic acid $\left(0.249 \mathrm{mg} \cdot \mathrm{g}^{-1}\right)$, and resveratrol $\left(1.256 \mathrm{mg} \cdot \mathrm{g}^{-1}\right)$; in the OS extract: kaempferol $\left(4.861 \mathrm{mg} \cdot \mathrm{g}^{-1}\right)$, rosmarinic acid $\left(0.043 \mathrm{mg} \cdot \mathrm{g}^{-1}\right)$, quercetin $\left(2.838 \mathrm{mg} \cdot \mathrm{g}^{-1}\right)$, and rutin $\left(2.156 \mathrm{mg} \cdot \mathrm{g}^{-1}\right)$.

\subsection{Antimicrobial Activity}

Figure 2 presents the microdilution method results of the analyzed extracts, expressed as bacterial (for bacteria-BGR\%) or mycelial growth rate (in case of fungi-MGR\%), calculated according to Formula (1). Meanwhile, Figure 3 shows the bacterial inhibition rate $(\mathrm{BIR} \%) /$ mycelial inhibition rate (MIR \%), calculated according to Formula (2).

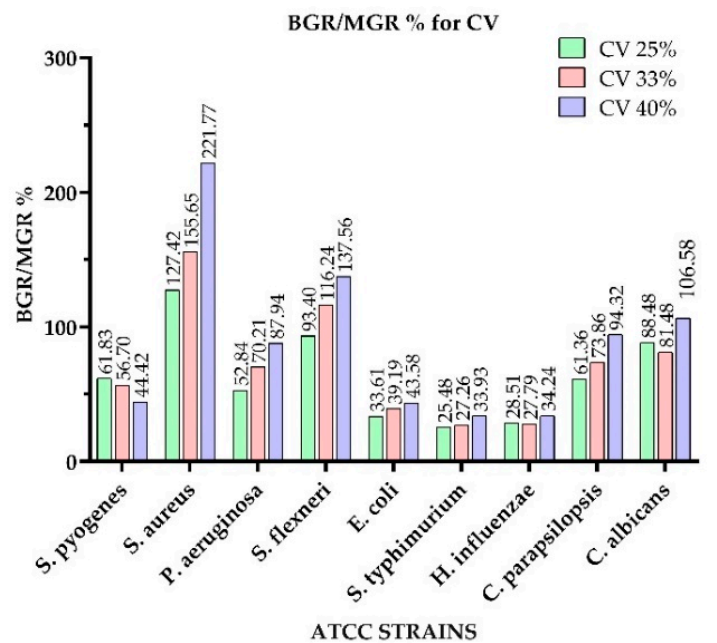

(A). Antimicrobial activity (expressed as BGR/MGR\%) of the CV extract.

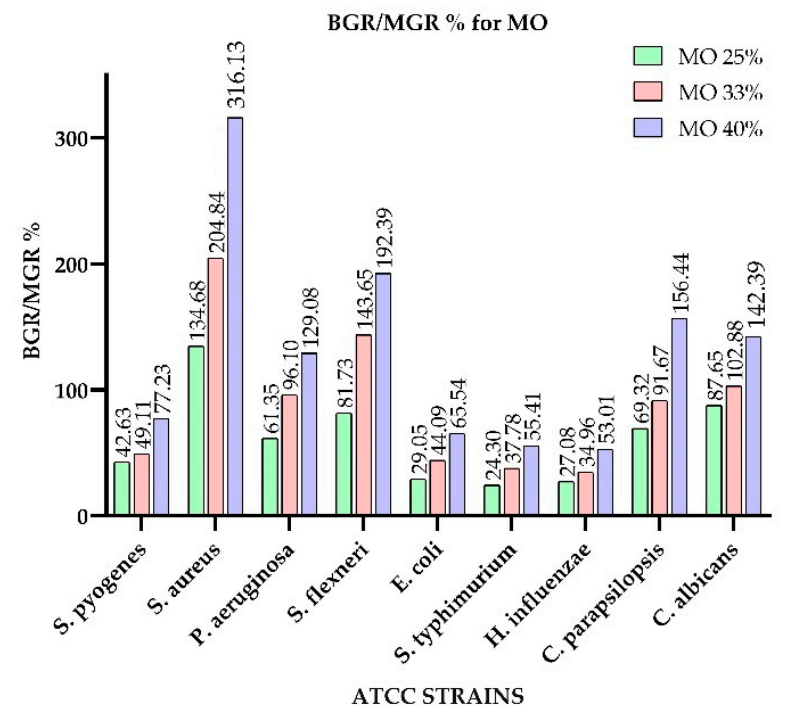

(C). Antimicrobial activity (expressed as BGR/MGR\%) of the MO extract.

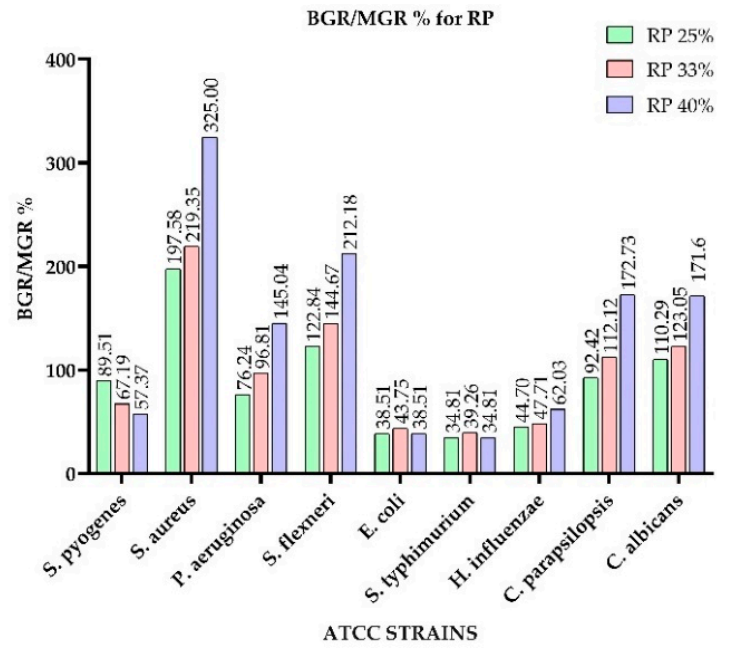

(B). Antimicrobial activity (expressed as BGR/MGR\%) of the RP extract.

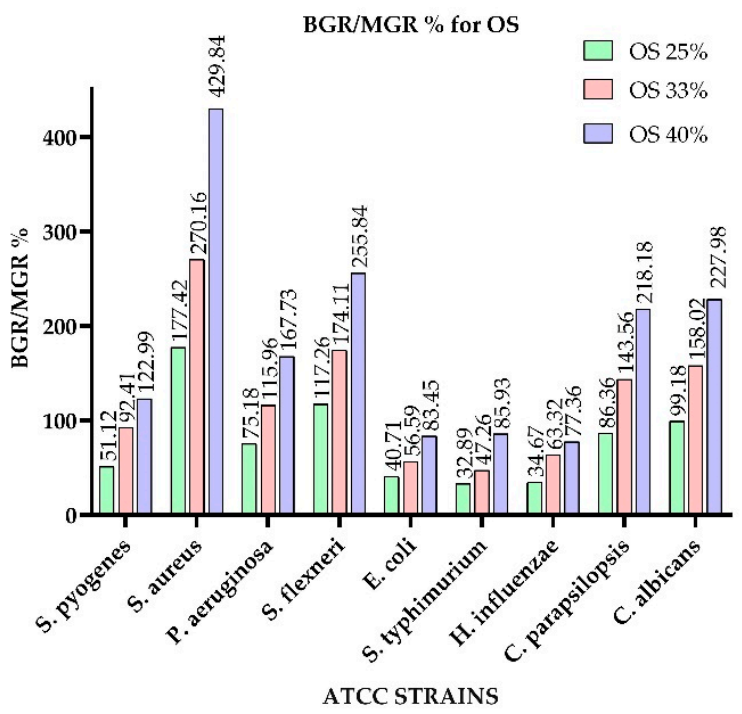

(D). Antimicrobial activity (expressed as BGR/MGR\%) of the OS extract.

Figure 2. Antimicrobial activity of analyzed extracts expressed as BGR/MGR (\%). (A). CV extract; (B). RP extract; (C). MO extract; (D). OS extract. 


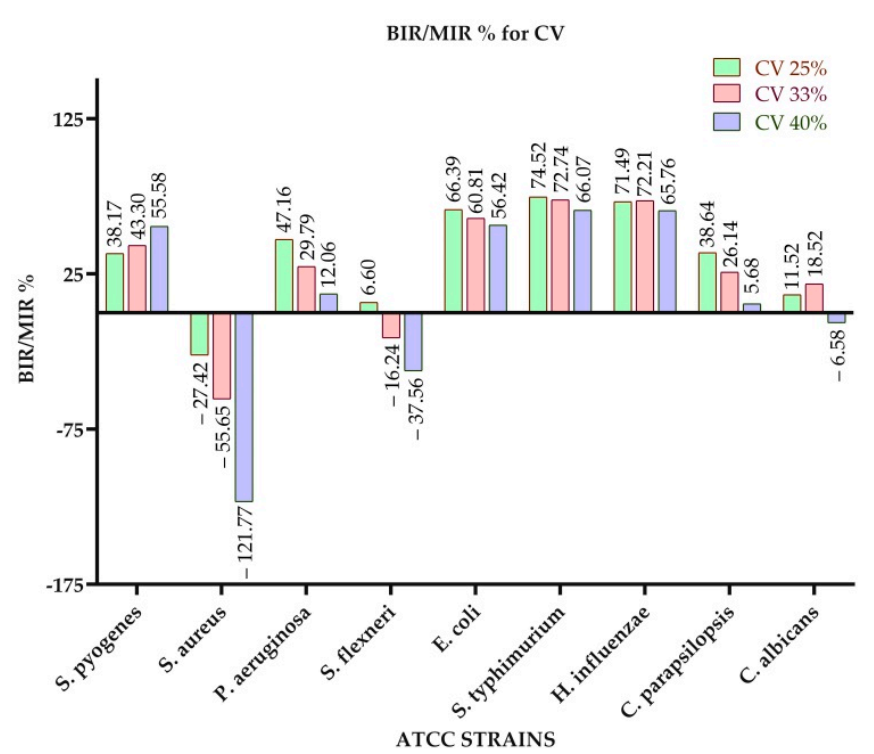

(A). Antimicrobial activity (expressed as BIR/MIR\%) of the $\mathrm{CV}$ extract.

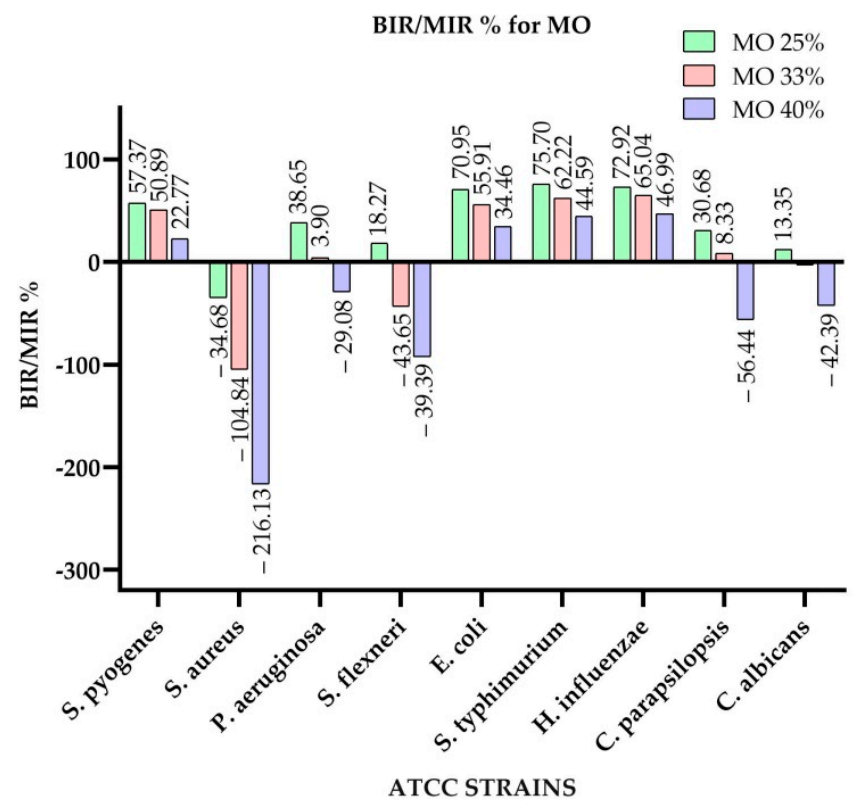

(C). Antimicrobial activity (expressed as BIR/MIR\%) of the MO extract.

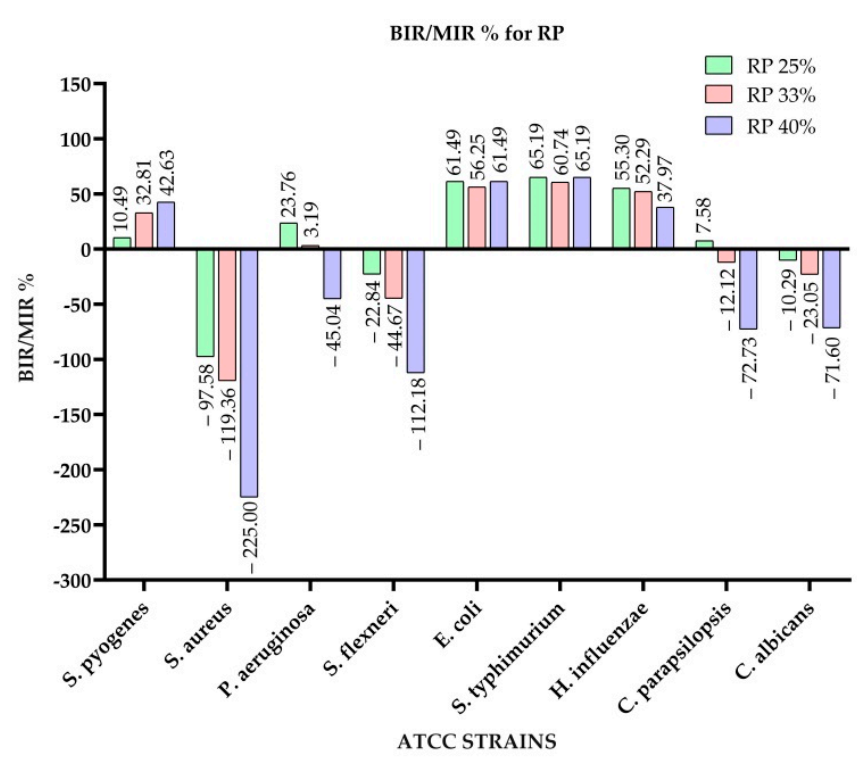

(B). Antimicrobial activity (expressed as BIR/MIR\%) of the RP extract.

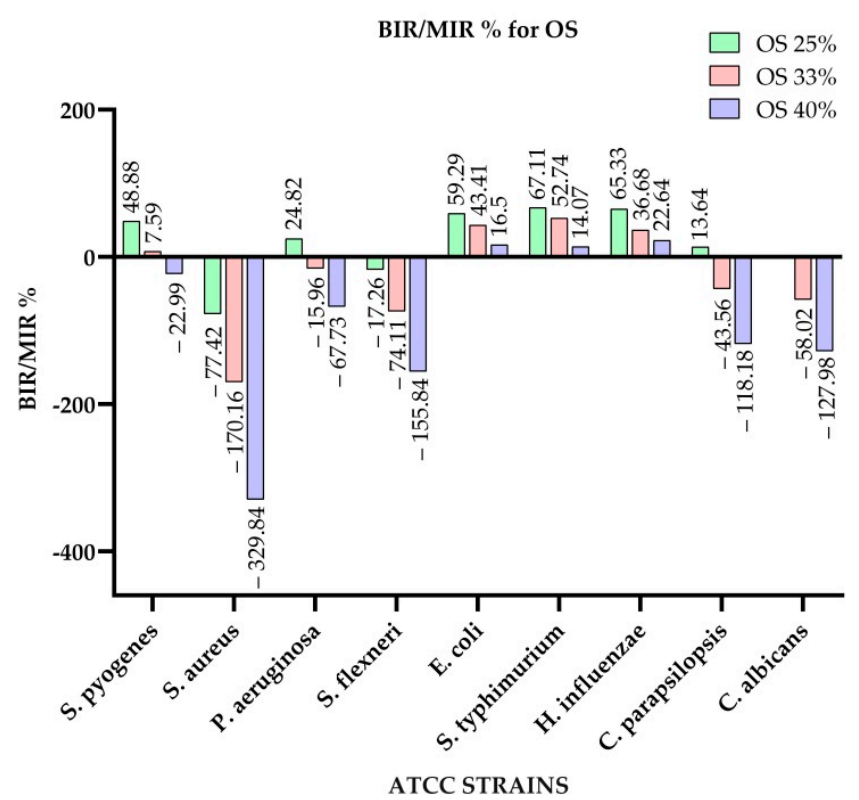

(D). Antimicrobial activity (expressed as BIR/MIR\%) of the OS extract.

Figure 3. Antimicrobial activity of extracts expressed as BIR/MIR (\%) calculated according to Formula (1). (A). CV extract; (B). RP extract; (C). MO extract; (D). OS extract.

Two indicators were calculated, BGR for MGR and BIR/MIR, to interpret the results, using the following formulas:

$$
\begin{gathered}
\mathrm{BGR} / \mathrm{MGR}=\frac{\mathrm{OD}_{\text {sample }}}{\mathrm{OD}_{\text {negative }} \text { control }} \times 100 \quad(\%) \\
\mathrm{BIR} / \mathrm{MIR}=100-\mathrm{BGR} / \mathrm{MGR}(\%)
\end{gathered}
$$

where OD sample-is the optical density at $540 \mathrm{~nm}$ as a mean value of triplicate readings for extracts and standards in the presence of selected strains; OD negative control一the 
optical density at $540 \mathrm{~nm}$ as a mean value of triplicate readings for the selected strains in $\mathrm{BHI}$.

A table containing the OD (optical density) values when different concentrations of extracts were applied on the screened strains is presented in the Supplementary Table S1.

Comparing the BGR percentages, the most sensitive ATCC strains, in the case of the CV extract, were: H. influenzae, S. typhimurium, E. coli, and S. pyogenes (Figure 2A). For $H$. influenzae, the bacterial growth rate (BGR\%), depending on the concentration of the extract tested (CV 25\%; CV 33\% and CV 40\%), varied from 28.51-34.24\% (Figure 2A), with a bacterial inhibition rate (BIR\%) ranging from $65.76-71.49 \%$ compared to the negative control (Figure 3A), while the BIR against S. typhimurium was 66.07-74.52\%.

The concentration influence trend was similar for the other sensitive strains. In $\mathrm{CV}$, BIR ranged between 38.17-55.58\% against S. pyogenes, and between $56.42 \%$ and $66.39 \%$ against E. coli. Regarding the antifungal activity, the fungal inhibition rate showed a higher effect on C. parapsilopsis than on C. albicans, values being different by $20 \%$.

$S$. aureus and $S$. flexneri were the only two ATCC strains on which the inhibitory effect of CV was not observed. The evolution of BIR\% in their case was negative, proving a bacterial boosting effect. The growth rate for $S$. aureus was concentration-dependent, ranging from $127.41 \%$ to $221.77 \%$. The bacterial growth effect on S. flexneri was demonstrated in the case of CV by BGR\% values ranging from $93.4 \%$ to $137.56 \%$ (Figure $2 \mathrm{~A}$ ).

To summarize the data regarding the RP antimicrobial activity presented in Figures 2B and 3B, RP was the most effective against S. pyogenes, E. coli, S. typhimurium, and $H$. influenzae with BIR values between $7.58 \%$ and $65.19 \%$ (Figure 3B). Regarding the other tested strains (S. aureus, P. aeruginosa, S. flexneri, and both Candida strains), RP had a proven growth-boosting effect. It had a BGR compared to control (\%) that varied from 197.58-325\% for S. aureus, 76.24-145.04\% for P. aeruginosa, 122.84-212.18\% for S. flexneri, and $92.42-172.73 \%$ MGR for C. parapsilopsis, and 110.29-171.60\% for C. albicans. It was noted that the boosting effect was influenced by the quantity of the extract tested, MGR growing together with the concentration (Figure 2B).

Concerning the three concentrations of the $\mathrm{MO}$ alcoholic extracts $\mathrm{MO} 25 \%, \mathrm{MO} 33 \%$, and $\mathrm{MO} 40 \%$ ), the results presented in Figures $2 \mathrm{C}$ and $3 \mathrm{C}$ show the best antimicrobial effect recorded against $S$. pyogenes (with BGR ranging from 42.63-77.23\%, and BIR 22.77-57.37\%), $E$. coli (with BGR values of 29.05-65.54\%, and BIR of 34.46-70.95\%) and S. typhimurium (BGR of $24.30-55.41 \%$, BIR of $46.99-72.52 \%$ ), depending on the concentration.

The boosting effect was linked to the concentration of the extracts. BGR\% ranging from $134.68 \%$ for MO $25 \%$ up to $316.13 \%$ for MO $40 \%$ for S. aureus, $61.35 \%$ for MO $25 \%$ up to $129.08 \%$ for MO $40 \%$ on P. aeruginosa, with values ranging from $81.73 \%$ for $\mathrm{MO} 25 \%$ and $192.39 \%$ for MO $40 \%$ for S. flexneri. Meanwhile, for both fungal strains, the percentages ranged from $69.32 \%$ in $\mathrm{MO} 25 \%$ up to $156.44 \%$ for $\mathrm{MO} 40 \%$ (Figure $2 \mathrm{C}$ ).

Regarding the effect of all three OS extracts tested (OS 25\%, OS 33\% and OS 40\%), the data obtained revealed a boosting effect, proved by the negative values of BIR on $S$. pyogenes, with BIR\% values ranging from $-22.99 \%$ when OS $40 \%$ was applied, $-77.42 \%$ to $-329.84 \%$ on $S$. aureus, $-15.96 \%$ to $-67.73 \%$ on $P$. aeruginosa, S. flexneri $-17.26 \%$ to $-155.84 \%$, and both fungal strains with MIR\% ranging from $-13 \%$ down to $-127 \%$. The inhibitory effect of the OS extract was proven against E. coli (MIR ranging from 16.25$59.29 \%$, S. typhimurium with BIR 67.11-14.07\%, and H. influenzae with $65.33-13.64 \%$. All the results for $\mathrm{BGR} / \mathrm{MGR} \%$ and $\mathrm{BIR} / \mathrm{MIR} \%$ values when the OS extract was used are presented in Figures 2D and 3D. The statistical analysis performed in Table 3 highlighted significant differences between the antimicrobial activity against the tested strains depending on extract matrices and concentration. 
Table 3. The efficiency of identified standards on the four sensitive strains selected.

\begin{tabular}{|c|c|c|c|c|c|c|c|c|}
\hline \multirow{2}{*}{ Strain/Component } & \multicolumn{2}{|c|}{ E. coli } & \multicolumn{2}{|c|}{ S. typhimurium } & \multicolumn{2}{|c|}{ P. aeruginosa } & \multicolumn{2}{|c|}{ S. pyogenes } \\
\hline & BGR (\%) & BIR (\%) & BGR (\%) & $\operatorname{BIR}(\%)$ & BGR (\%) & BIR (\%) & BGR (\%) & BIR (\%) \\
\hline Gallic acid 500 & 63.02 & 36.97 & 54.04 & 45.95 & 51.28 & 48.71 & 81.83 & 18.16 \\
\hline Gallic acid 50 & 51.35 & 48.64 & 39.58 & 60.41 & 41.97 & 58.02 & 76.1 & 23.89 \\
\hline Protocatechuic acid 500 & 49.53 & 50.46 & 37.91 & 62.08 & 42.84 & 57.15 & 53.96 & 46.03 \\
\hline Protocatechuic acid 50 & 47.23 & 52.76 & 38.02 & 61.97 & 42.01 & 57.98 & 59.33 & 40.66 \\
\hline Caffeic acid500 & 54.89 & 45.1 & 47.36 & 52.63 & 44.52 & 55.47 & 49.81 & 50.18 \\
\hline Caffeic acid50 & 59.78 & 40.21 & 42.28 & 57.71 & 47.41 & 52.58 & 56.94 & 43.05 \\
\hline Epicatechin 500 & 58.89 & 41.1 & 43.2 & 56.79 & 45.27 & 54.72 & 61.58 & 38.41 \\
\hline Epicatechin 50 & 90.02 & 9.97 & 92.46 & 7.53 & 91.29 & 8.7 & 90.66 & 9.33 \\
\hline Coumaric acid 500 & 95.15 & 4.84 & 92.76 & 7.23 & 87.4 & 12.59 & 99.05 & 0.94 \\
\hline Coumaric acid 50 & 97.01 & 2.99 & 88.08 & 11.91 & 89.35 & 10.64 & 99.27 & 0.72 \\
\hline Ferulic acid 500 & 94.07 & 5.92 & 90.79 & 9.2 & 96.61 & 3.38 & 99.18 & 0.81 \\
\hline Ferulic acid 50 & 85.95 & 14.04 & 83.14 & 16.85 & 98.03 & 1.96 & 98.15 & 1.84 \\
\hline Rutin 500 & 77.1 & 22.89 & 52.3 & 47.69 & 52.25 & 47.74 & 66.18 & 33.81 \\
\hline Rutin 50 & 77.1 & 22.89 & 51.45 & 48.54 & 65.6 & 34.39 & 90.03 & 9.96 \\
\hline Rosmarinic acid 500 & 104.35 & -4.35 & 86.02 & 13.97 & 91.71 & 8.28 & 94.95 & 5.04 \\
\hline Rosmarinic acid 50 & 123.05 & -23.05 & 90.47 & 9.52 & 97.08 & 2.91 & 98.64 & 1.35 \\
\hline Resveratrol 500 & 113.57 & -13.57 & 83.93 & 16.06 & 94.53 & 5.46 & 99.09 & 0.9 \\
\hline Resveratrol 50 & 66.83 & 33.16 & 51.06 & 48.93 & 77.99 & 22.01 & 90.3 & 9.69 \\
\hline Quercetin 500 & 87.12 & 12.87 & 44.27 & 55.72 & 67.44 & 32.55 & 63.88 & 36.11 \\
\hline Quercetin 50 & 93.53 & 6.46 & 52.56 & 47.43 & 88.43 & 11.56 & 90.53 & 9.46 \\
\hline Kaempferol 500 & 51.63 & 48.36 & 38.43 & 61.56 & 40.63 & 59.36 & 52.02 & 47.97 \\
\hline Kaempferol 50 & 94.17 & 5.82 & 85.06 & 14.93 & 93.01 & 6.98 & 84.62 & 15.37 \\
\hline
\end{tabular}

After the antimicrobial assays of extracts, the chemical compounds responsible for the antimicrobial effect were tested individually. In this regard, standard chemical substances identified by LC as the main polyphenol compounds in the extracts were tested on the selected four sensitive strains, eliminating the bacteria and fungi that proved to be unaffected by the tested extracts.

Table 3 presents the bacterial growth rate (BGR\%) and the bacterial inhibition rate (BIR\%) of individual polyphenol standards at 50 and $500 \mathrm{mg} \cdot \mathrm{g}^{-1}$.

The MICs $(\mu \mathrm{L} / 100 \mathrm{~mL})$ values, defined as the lowest concentration of the compounds to inhibit the growth of microorganisms, $\mathrm{CV}, \mathrm{RP}, \mathrm{MO}$, and OS extracts and chemical compounds, are presented in Tables 4 and 5 . 
Table 4. The MIC ( $\mu \mathrm{L} / 100 \mathrm{~mL})$ for plant extracts $\mathrm{CV}, \mathrm{RP}, \mathrm{MO}$, and OS.

\begin{tabular}{|c|c|c|c|c|c|c|c|c|c|}
\hline & $\begin{array}{c}S . \\
\text { pyogenes }\end{array}$ & S. aureus & $\begin{array}{c}P . \\
\text { aeruginosa }\end{array}$ & S. flexneri & E. coli & $\begin{array}{c}S . \\
\text { typhimurium }\end{array}$ & $\begin{array}{c}H . \\
\text { influenzae }\end{array}$ & $\begin{array}{l}\text { C.parap- } \\
\text { silopsis }\end{array}$ & C. albicans \\
\hline $\mathrm{CV}$ & 25 & 25 & 25 & 25 & 25 & 25 & 25 & 25 & 25 \\
\hline $\mathrm{CV}$ & 33 & 33 & 33 & 33 & 33 & 33 & 33 & 33 & 33 \\
\hline $\mathrm{CV}$ & 40 & 40 & 40 & 40 & 40 & 40 & 40 & 40 & 40 \\
\hline $\mathrm{RP}$ & 25 & 25 & 25 & 25 & 25 & 25 & 25 & 25 & 25 \\
\hline $\mathrm{RP}$ & 33 & 33 & 33 & 33 & 33 & 33 & 33 & 33 & 33 \\
\hline RP & 40 & 40 & 40 & 40 & 40 & 40 & 40 & 40 & 40 \\
\hline $\mathrm{MO}$ & 25 & 25 & 25 & 25 & 25 & 25 & 25 & 25 & 25 \\
\hline $\mathrm{MO}$ & 33 & 33 & 33 & 33 & 33 & 33 & 33 & 33 & 33 \\
\hline $\mathrm{MO}$ & 40 & 40 & 40 & 40 & 40 & 40 & 40 & 40 & 40 \\
\hline OS & 25 & 25 & 25 & 25 & 25 & 25 & 25 & 25 & 25 \\
\hline OS & 33 & 33 & 33 & 33 & 33 & 33 & 33 & 33 & 33 \\
\hline OS & 40 & 40 & 40 & 40 & 40 & 40 & 40 & 40 & 40 \\
\hline
\end{tabular}

The samples that had no inhibition effect, causing a mass growth of the strain, are marked in dark grey color. The light gray color represents the samples in which the MIC was found, but subsequent concentrations showed a potentiating effect. Therefore, the effect decreased together with the concentration. The white color highlights the samples where the MIC was determined. The effect was maintained together with an increase in concentration.

Table 5. The MIC ( $\mu \mathrm{L} / 100 \mathrm{~mL})$ for polyphenol standards against the most sensitive strains.

\begin{tabular}{|c|c|c|c|c|}
\hline & E. coli & S. typhimurium & P. aeruginosa & S. pyogenes \\
\hline Gallic acid & 500 & 500 & 500 & 500 \\
\hline Gallic acid & 50 & 50 & 50 & 50 \\
\hline Protocatechuic acid & 500 & 500 & 500 & 500 \\
\hline Protocatechuic acid & 50 & 50 & 50 & 50 \\
\hline Caffeic acid & 500 & 500 & 500 & 500 \\
\hline Caffeic acid & 50 & 50 & 50 & 50 \\
\hline Epicatechin & 500 & 500 & 500 & 500 \\
\hline Epicatechin & 50 & 50 & 50 & 50 \\
\hline Coumaric acid & 500 & 500 & 500 & 500 \\
\hline Coumaric acid & 50 & 50 & 50 & 50 \\
\hline Ferulic acid & 500 & 500 & 500 & 500 \\
\hline Ferulic acid & 50 & 50 & 50 & 50 \\
\hline Rutin & 500 & 500 & 500 & 500 \\
\hline Rutin & 50 & 50 & 50 & 50 \\
\hline Rosmarinic acid & 500 & 500 & 500 & 500 \\
\hline Rosmarinic acid & 50 & 50 & 50 & 50 \\
\hline Resveratrol & 500 & 500 & 500 & 500 \\
\hline Resveratrol & 50 & 50 & 50 & 50 \\
\hline Quercetin & 500 & 500 & 500 & 500 \\
\hline Quercetin & 50 & 50 & 50 & 50 \\
\hline Kaempferol & 500 & 500 & 500 & 500 \\
\hline Kaempferol & 50 & 50 & 50 & 50 \\
\hline
\end{tabular}

The samples that had no inhibition effect, causing a mass growth, are marked in dark grey color. The light gray color represents the samples in which the MIC was found. However, subsequent concentrations showed a potentiating effect. Therefore, the effect decreased with the concentration. The white color highlights the samples in which the MIC was determined. The effect was maintained together with an increase in concentration.

According to the data presented in Table 4, no inhibition effect, causing a mass growth (marked in dark grey color) regardless of the concentration tested, was observed against S. aureus. Regarding the most extracts and concentrations tested, the MIC value varied between $25-40 \mu \mathrm{L} / 100 \mathrm{~mL}$, but subsequent concentrations showed a potentiating effect. Therefore, the effect decreased together with the concentration. The MIC of the CV and RP extract against $S$. pyogenes, respectively, and the MO extracts against $P$. aeruginosa was $25 \mu \mathrm{L} / 100 \mathrm{~mL}$. The effect was maintained with an increase in concentration (white color).

Regarding the polyphenols standards, the MIC of gallic acid, ferulic acid, and resveratrol was $50 \mathrm{mg} \cdot \mathrm{g}^{-1}$ against $E$. coli. However, the effect decreased together with the concentration. The values tested were not the correct quantity to define MIC in the case of the coumaric acid. For the rest of the standards, namely protocatechuic acid, caffeic acid, 
epicatechin, rutin, rosmarinic acid, quercetin, and kaempferol, $50 \mathrm{mg} \cdot \mathrm{g}^{-1}$ proved to be the MIC. The effect was maintained together with an increase in concentration (Table 5).

For S. typhimurium, the results showed no effect for coumaric and ferulic acids, potentiating for gallic and caffeic acids, and MIC at $50 \mathrm{mg} \cdot \mathrm{g}^{-1}$ when protocatechuic acid, epicatechin, rutin, rosmarinc acid, resveratrol, quercetin, and kaempferol were used.

The results on P. aeruginosa showed that only ferulic and rosmarinic acids did not affect at 50 and $500 \mathrm{mg} \cdot \mathrm{g}^{-1}$. Other polyphenols presented an MIC at $50 \mathrm{mg} \cdot \mathrm{g}^{-1}$.

Regarding the effect of the standards against $S$. pyogenes, gallic acid and resveratrol had a strain-boosting effect, while coumaric, ferulic, and rosmarinic acids had no effect. Epicatechin, rutin, quercetin, kaempferol, and protocatechuic acid proved an inhibitory effect on all tested strains, and the MIC was $50 \mathrm{mg} \cdot \mathrm{g}^{-1}$.

The analysis of correlation (Table 6) between the chemical composition and the antimicrobial effect of the plant extracts against the analyzed strains proved a moderate $(r>0.5)$ positive correlation between the pairs. Rosmarinic acid and S. pyogenes $(r=0.526)$, rosmarinic acid and S. typhimurium $(\mathrm{r}=0.568)$, quercetin and C. albicans $(\mathrm{r}=0.553)$, quercetin and $S$. pyogenes $(r=0.605)$, suggesting possible antimicrobial activity generated by these chemical components.

Other strong $(\mathrm{r}>0.7)$ positive correlations were recorded between the following pairs:

- $\quad$ S. pyogenes and S. typhimurium $(r=0.914), \mathrm{H}$. influenzae $(r=0.817)$, C. parapsilopsis $(r=0.715)$, C. albicans $(r=0.795)$.

- $\quad$ S. aureus and P. aeruginosa $(r=0.984)$.

- S. flexneri and S. typhimurium $(r=0.720), H$. influenzae $(r=0.936), C$. parapsilopsis $(\mathrm{r}=0.988)$, C. albicans $(\mathrm{r}=0.920)$.

- S. typhimurium and $\mathrm{H}$. influenzae $(\mathrm{r}=0.777)$, C. parapsilopsis $(\mathrm{r}=0.728), \mathrm{C}$. albicans $(\mathrm{r}=0.737)$.

- H. influenzae and C. parapsilopsis $(r=0.958)$, C. albicans $(r=0.946)$.

- C. parapsilopsis and C. albicans $(r=0.941)$.

- Gallic acid and rutin $(\mathrm{r}=0.896)$, resveratrol $(\mathrm{r}=0.848)$.

- Protocatechuic acid and epicatechin $(r=0.750)$, resveratrol $(r=0.826)$.

- Caffeic acid and epicatechin $(r=0.959)$, coumaric acid $(r=0.986)$, kaempferol $(r=0.943)$.

- Epicatechin and coumaric acid $(r=0.990)$, kaempferol $(r=0.824)$.

- Coumaric acid and kaempferol $(\mathrm{r}=0.874)$.

- Ferulic acid and quercetin $(r=0.810)$; rutin and resveratrol $(r=0.977)$.

- Rosmarinic acid and quercetin $(r=0.930)$.

- A strong negative correlation was highlighted between the following pairs:

- Gallic acid and kaempferol ( $\mathrm{r}=-0.753)$; protocatechuic acid and ferulic acid $(\mathrm{r}=-0.703)$; caffeic acid and rosmarinic acid $(\mathrm{r}=-0.794$; epicatechin and rosmarinic acid $(\mathrm{r}=-0.717)$; coumaric acid and rosmarinic acid $(\mathrm{r}=-0.790)$; coumaric acid and quercetin $(\mathrm{r}=-0.706)$. 
Table 6. Correlations between variables (OD mean values of spectrophotometric determination of antimicrobial activity and the polyphenol concentration analyzed by LC).

\begin{tabular}{|c|c|c|c|c|c|c|c|c|c|c|c|c|c|c|c|c|c|c|c|c|}
\hline & $\begin{array}{c}s . \\
\text { pyogenes }\end{array}$ & S. aureus & $\begin{array}{c}P . \\
\text { aeruginosa }\end{array}$ & S.flexneri & E. coli & $\begin{array}{l}\text { S. typh- } \\
\text { murrium }\end{array}$ & H. ifluzae & $\begin{array}{l}\text { C. parp- } \\
\text { silopsis }\end{array}$ & C. albcans & Gallic acid & $\begin{array}{l}\text { Protocatechuic } \\
\text { acid }\end{array}$ & $\begin{array}{c}\text { Caffeic } \\
\text { acid }\end{array}$ & Epicatechin & $\underset{\text { acid }}{\text { Coumaric }}$ & $\begin{array}{c}\text { Ferulic } \\
\text { acid }\end{array}$ & Rutin & $\begin{array}{c}\text { Rosma- } \\
\text { rinic } \\
\text { acid }\end{array}$ & $\begin{array}{c}\text { Resvera- } \\
\text { trol }\end{array}$ & Quercetin & $\begin{array}{l}\text { Kaem } \\
\text { pferol }\end{array}$ \\
\hline S. pyogenes & 1 & & & & & & & & & & & & & & & & & & & \\
\hline S. aureus & 0.618 & 1.000 & & & & & & & & & & & & & & & & & & \\
\hline P. aeruginosa & 0.614 & 0.984 & 1.000 & & & & & & & & & & & & & & & & & \\
\hline S. flexneri & 0.685 & 0.392 & 0.320 & 1.000 & & & & & & & & & & & & & & & & \\
\hline E. coli & 0.247 & 0.008 & 0.090 & -0.029 & 1.000 & & & & & & & & & & & & & & & \\
\hline S. typhimurium & 0.914 & 0.693 & 0.693 & 0.720 & 0.345 & 1.000 & & & & & & & & & & & & & & \\
\hline H. influenzae & 0.817 & 0.512 & 0.465 & 0.936 & 0.089 & 0.777 & 1.000 & & & & & & & & & & & & & \\
\hline C. parapsilopsis & 0.715 & 0.444 & 0.366 & 0.988 & -0.014 & 0.728 & 0.958 & 1.000 & & & & & & & & & & & & \\
\hline C. albicans & 0.795 & 0.517 & 0.429 & 0.920 & -0.102 & 0.737 & 0.946 & 0.941 & 1.000 & & & & & & & & & & & \\
\hline Gallic acid & -0.025 & -0.060 & -0.037 & -0.011 & 0.080 & -0.045 & 0.064 & -0.017 & -0.023 & 1.000 & & & & & & & & & & \\
\hline $\begin{array}{c}\text { Protocatechuic } \\
\text { acid }\end{array}$ & -0.258 & -0.075 & -0.018 & -0.066 & -0.014 & -0.081 & -0.082 & -0.071 & -0.185 & 0.437 & 1.000 & & & & & & & & & \\
\hline Caffeic acid & -0.280 & -0.066 & -0.035 & -0.108 & -0.137 & -0.095 & -0.211 & -0.112 & -0.212 & -0.523 & 0.532 & 1.000 & & & & & & & & \\
\hline Epicatechin & -0.302 & -0.077 & -0.033 & -0.105 & -0.108 & -0.098 & -0.190 & -0.111 & -0.226 & -0.263 & 0.750 & 0.959 & 1.000 & & & & & & & \\
\hline Coumaric acid & -0.325 & -0.100 & -0.062 & -0.137 & -0.149 & -0.129 & -0.238 & -0.144 & -0.251 & -0.375 & 0.659 & 0.986 & 0.990 & 1.000 & & & & & & \\
\hline Ferulic acid & 0.543 & 0.415 & 0.374 & 0.395 & 0.296 & 0.433 & 0.508 & 0.440 & 0.495 & -0.472 & -0.703 & -0.290 & -0.462 & -0.428 & 1.000 & & & & & \\
\hline Rutin & 0.044 & 0.081 & 0.119 & 0.107 & 0.188 & 0.095 & 0.206 & 0.118 & 0.067 & 0.896 & 0.699 & -0.209 & 0.070 & -0.065 & -0.418 & 1.000 & & & & \\
\hline Rosmarinc acid & 0.526 & 0.359 & 0.341 & 0.380 & 0.371 & 0.393 & 0.568 & 0.420 & 0.475 & 0.484 & -0.289 & -0.794 & -0.717 & -0.790 & 0.542 & 0.434 & 1.000 & & & \\
\hline Quercetin & 0.605 & 0.441 & 0.413 & 0.448 & 0.393 & 0.471 & 0.631 & 0.497 & 0.553 & 0.134 & -0.472 & -0.651 & -0.667 & -0.706 & 0.810 & 0.143 & 0.930 & -0.062 & 1.000 & \\
\hline Kaempferol & -0.133 & 0.034 & 0.051 & -0.006 & -0.071 & 0.018 & -0.090 & -0.001 & -0.081 & -0.753 & 0.261 & 0.943 & 0.824 & 0.874 & 0.032 & -0.435 & -0.692 & -0.298 & -0.443 & 1.000 \\
\hline
\end{tabular}




\section{Discussion}

\subsection{Chemical Composition of Extracts}

Other authors previously studied the polyphenolic content of the RP and MA samples, and the results were falling within the range of values obtained in this study. Thus, in the case of RP, Marinas et al. (2014) [29] found a content of $26.67 \mathrm{mg} \mathrm{GAE} / \mathrm{g}$, and for MA, the level was reported at $14.8 \mathrm{mg}$ GAE/g [30]. Higher values of phenolic compounds in the flowers $(0.77 \mathrm{mg} \mathrm{GAE} / \mathrm{mL})$ were observed compared to syrup $60^{\circ}$ Brix $(0.06 \mathrm{mg} \mathrm{GAE} / \mathrm{mL})$ and R. pseudoacacia syrup $70^{\circ}$ Brix $(0.14 \mathrm{mg}$ GAE $/ \mathrm{mL})$ [31]. Serbian RP showed values of $74.28 \pm 1.73$ for TPC (mg GAE/g) [29], while Arnold et al. (2015) [32] reported a phenolic content of $20.55 \pm 2.56 \mathrm{mg} \mathrm{GAE} / \mathrm{g}$ in the OS extract.

Previous studies showed that M. officinalis L., contained coumarins, flavonoids, steroids and saponins, phenolic acids, volatile components, fats, alcohols, uric acid, and other chemical compounds [33-35]. These compounds have antiinflammatory, swelling, and antitumour properties, as well as therapeutic effects against hemorrhoids, thrombophlebitis, and varicose veins [33,36-38].

Another study in Poland reported the following key compounds in the MO extract: coumaric acid $\left(0.443 \mathrm{mg} \cdot \mathrm{g}^{-1}\right)$, protocatechuic acid $\left(0.149 \mathrm{mg} \cdot \mathrm{g}^{-1}\right)$, ferulic acid $\left(0.444 \mathrm{mg} \cdot \mathrm{g}^{-1}\right)$, and caffeic acid $\left(0.849 \mathrm{mg} \cdot \mathrm{g}^{-1}\right)$, while the gallic acid was found in a concentration of $0.119 \mathrm{mg} \cdot \mathrm{g}^{-1}$ [39]. In an ethanol $96 \%$ extract, Molnar et al. (2017) [40] found the coumarin concentration in whole $M$. officinalis to be $3.163 \mathrm{mg} \cdot \mathrm{g}^{-1}$. In an ethanol $50 \%$ extract, the concentration was $1.464 \mathrm{mg} \cdot \mathrm{g}^{-1}$. In a review, Al-Snafi et al. (2020) [41] cited Safapour et al. (2015) [8] concerning HPLC analysis that revealed the flower powder of MO contained $9.7 \mathrm{mg} \cdot \mathrm{g}^{-1}$ gallic acid, $99 \mathrm{mg} \cdot \mathrm{g}^{-1}$ catechin, $21.9 \mathrm{mg} \cdot \mathrm{g}^{-1}$ caffeic acid, $0.86 \mathrm{mg} \cdot \mathrm{g}^{-1}$ chlorogenic acid, $1.13 \mathrm{mg} \cdot \mathrm{g}^{-1}$ quercetin, $548.9 \mathrm{mg} \cdot \mathrm{g}^{-1}$ cinnamic acid, $289 \mathrm{mg} \cdot \mathrm{g}^{-1}$ coumarin, and $126 \mathrm{mg} \cdot \mathrm{g}^{-1} \mathrm{p}$-coumaric acid. This research was also confirmed by Jasicka-Misiak et al. (2017) [42].

Our findings are in accord with Călina et al. (2013) [43], who proved that flavonoids, such as rutin (ruthoside) and hyperoside were found in methanolic extracts from flowers, leaves, bark, and seeds of RP from western Romania. Their findings showed that the flower extract contained more hyperoside $\left(0.9 \mathrm{mg} \cdot \mathrm{g}^{-1}\right)$ than the leaf extract $\left(0.17 \mathrm{mg} \cdot \mathrm{g}^{-1}\right)$. On the other hand, in rutin, the leaves contained almost six times more rutin than the flowers $\left(0.98 \mathrm{mg} \cdot \mathrm{g}^{-1}\right.$ vs. $\left.0.17 \mathrm{mg} \cdot \mathrm{g}^{-1}\right)$. The literature also cites the chemical content of RP wood in gallic acid with values ranging from $27-296 \mathrm{mg} \cdot \mathrm{g}^{-1}$ [43]. The same two primary components were found in the $\mathrm{CV}$ extract, the difference being the smaller concentration. According to the literature, the main bioactive components found in the RP flowers include flavonoids, phenolics, ascorbic acid, polysaccharide, and some microelements [44-46].

Another study performed in Serbia [47] showed gallic acid in RP $\left(58.74 \mathrm{mg} \cdot \mathrm{g}^{-1}\right)$.

Ferrante et al. (2020) [15] studied the OS extracts from a chemical point of view and found that the main polyphenols identified were gallic acid $\left(1.17 \mathrm{mg} \cdot \mathrm{g}^{-1}\right)$, catechin $\left(13.06 \mathrm{mg} \cdot \mathrm{g}^{-1}\right)$, epicatechin $\left(1.4 \mathrm{mg} \cdot \mathrm{g}^{-1}\right)$, and rutin $\left(2.92 \mathrm{mg} \cdot \mathrm{g}^{-1)}\right.$. They appeared in almost similar ranges to our findings.

According to the literature, the main bioactive components found in Acacia flowers include flavonoids, phenols, ascorbic acid, polysaccharides, and some trace elements. Ferrante et al. (2020) [48] made a study on two types of OS extracts and discovered that in case of the hydroalcoholic extract, the gallic content was $227.25 \pm 9.11 \mathrm{mg} \cdot \mathrm{g}^{-1}$. Meanwhile, the resveratrol content was $61.82 \pm 6.99 \mathrm{mg} \cdot \mathrm{g}^{-1}$. The data presented in their study support our findings.

\subsection{Antimicrobial Activity}

Regarding the antimicrobial effect on the ATCC 19615 strain of S. pyogenes, the OS extract was the most effective while the CV was the least effective. The OS and RP demonstrated an inhibitory effect on the growth of the $S$. pyogenes mass, while $\mathrm{MO}$ and $\mathrm{CV}$ proved a strain-boosting effect. Rosu et al. (2012) [49] showed the antimicrobial effect of the RP 
extracts obtained from different plant parts against P. aeruginosa. Ferrante et al. (2020) [15] demonstrated the lack of antibacterial effect of the OS extract on S. pyogenes.

Our results on the ATCC strain of $S$. aureus showed the following classification: $\mathrm{MO}>\mathrm{RP}>\mathrm{CV}>\mathrm{OS}$. MO and RP have demonstrated an inhibitory effect, and CV proved a strain-boosting effect with a mycelial growth rate, BGR (\%), up to $223.96 \%$. The same effect was present in the case of OS, with a mycelial growth rate BGR (\%) up to and $442.97 \%$, values presented in Figure 2. These findings aligned with research by Marinas et al. (2014) [29], which proved that RP had an inhibitory effect on S. aureus ATCC and MRSA strains, while Sisay et al. (2019) [50] showed the effect of $M$. elegans against $S$. aureus. Ferrente et al. (2020) [15] demonstrated a medium effect on S. aureus, with a MIC of $99.21 \mu \mathrm{g} / \mathrm{mL}$ in the case of the OS extract.

P. aeruginosa was inhibited by $\mathrm{MO}$ and RP. At the same time, $\mathrm{CV}$ and $\mathrm{OS}$ stimulated its growth (MO $\downarrow>\mathrm{RP} \downarrow>\mathrm{CV} \uparrow>\mathrm{OS} \uparrow$ ), with values relative to the negative control. Other studies reported the same findings on RP [48,50] and OS [51] against P. aeruginosa. Karakas et al. (2012) [52] proved an inhibitory effect of the MO extract, which would justify the use of MO in folk medicine as part of inflammation-related therapy (caused by P. aeruginosa).

The development of E. coli colonies was inhibited by RP and OS and was stimulated by $\mathrm{CV}$ and $\mathrm{MO}(\mathrm{RP} \downarrow>\mathrm{OS} \downarrow>\mathrm{CV} \uparrow>\mathrm{MO} \uparrow)$. The good antibacterial effect against $E$. coli was also demonstrated [30,32] for RP and MO [50]. In the case of MO, a medium effect on E. coli was observed [51], while our studies are supported by Ferrente et al. (2020) [15], who proved a promising effect of OS on three E. coli strains, with concentrations ranging from $31-250 \mu \mathrm{g} / \mathrm{mL}$.

The analyzed extracts had no inhibitory effect on $S$. flexneri $(\mathrm{MO} \uparrow>\mathrm{CV} \uparrow>\mathrm{RP} \uparrow>\mathrm{OS} \uparrow)$. This finding is supported by Sisay et al. (2019) [50].

S. aureus was not inhibited by the studied extracts. All extracts had a colony-stimulating action ( $\mathrm{RP} \uparrow>\mathrm{CV} \uparrow>\mathrm{MO} \uparrow>\mathrm{OS} \uparrow$ ), being one of the few microorganisms more difficult to control [52]. In the cited literature [53], MO proved a weak effect on S. aureus, RP showed no effect on $S$. cholerae in any of the four types of extracts tested, and OS proved no effect against S. aureus (PeruMycA 7) in concentrations higher than $250 \mu \mathrm{g} / \mathrm{mL}[1,29,31]$.

All the extracts had the effect of stimulating the growth of $H$. influenzae and C. parapsilopsis, and therefore, we conclude that the effect was a boosting one (H. influenzae: $\mathrm{CV} \uparrow>\mathrm{MO} \uparrow>\mathrm{RP} \uparrow>\mathrm{OS} \uparrow ; \mathrm{C}$. parapsilopsis: $\mathrm{CV} \uparrow>\mathrm{MO} \uparrow>\mathrm{RP} \uparrow>\mathrm{OS} \uparrow)$.

On $C$. albicans colonies, only the CV extract had an inhibitory effect, with all the other extracts stimulating the fungal mass development (C. albicans: $\mathrm{CV} \downarrow>\mathrm{MO} \uparrow>\mathrm{RP} \uparrow>\mathrm{OS} \uparrow$ ). The same effect was noted, according to Ferrente et al. (2020) [48], on C. albicans (YEPGA 6183), with values ranging from 7-11 $\mu \mathrm{g} / \mathrm{mL}$. In other studies, RP proved no effect either [49].

Our findings showed that the efficacy of the extracts and standards tested, expressed as strain mass loss or mass growth, was closely correlated with the concentration.

In terms of efficacy on S. pyogenes, regarding the standard polyphenols (Table 3), the BGR $\%$ values classification was caffeic acid 49\% (present in MO, OS) $>$ kaempferol $52 \%$ (present in MO, OS) $>$ protocatechuic acid 53\% (present in RP, MO) $>$ epicatechin $61 \%$ (present in $\mathrm{MO}, \mathrm{RP}$ ) $>$ quercetin $63 \%$ (present in $\mathrm{OS}, \mathrm{RP}$ ) $>$ rutin $66 \%$ (present in RP).

According to this phase of our research, we may assume that the effectiveness of the OS extract is given by the amount of caffeic acid, kaempferol, quercetin.

Our results on the ATCC S. typhimurium proved, from the point of view of the antimicrobial efficacy of the extracts, the following classification: $\mathrm{CV}>\mathrm{MO}>\mathrm{RP}>\mathrm{OS}$.

According to the data presented in Table 3, regarding the efficacy of the extracts on $S$. typhimurium, the most significant effect was shown by protocatechuic acid $(\mathrm{MO})>$ gallic acid $(\mathrm{RP}, \mathrm{CV})>$ caffeic acid $(\mathrm{MO})>$ quercetin $(\mathrm{OS})>\operatorname{rutin}(\mathrm{MO}, \mathrm{RP}, \mathrm{CV})>$ kaempferol $(\mathrm{OS}$, $\mathrm{MO}, \mathrm{CV})$. These results correlated with the results obtained in the first part of our study, which emphasized the antibacterial effect of the extracts against $S$. typhimurium, with the data presented in Table 3.

Regarding the efficacy of the selected polyphenols on P. aeruginosa, we observed that the greatest inhibition was proved by kaempferol (MO, OS). It was followed by 
protocatechuic acid (MO, RP), caffeic acid (MO, OS), epicatechin (MO, RP), gallic acid (RP $\uparrow$ with concentration), rutin (RP), and quercetin (OS).

MO had in its composition the following polyphenols with antimicrobial activity on $P$. aeruginosa: kaempferol, protocatechuic acid, caffeic acid, and epicatechins.

The development of E. coli colonies was inhibited by RP and OS and was stimulated by $\mathrm{CV}$ and $\mathrm{MO}$ (RP $\downarrow>\mathrm{OS} \downarrow>\mathrm{CV} \uparrow>\mathrm{MO} \uparrow$ ).

On the development of $E$. coli, the most effective inhibitor was protocatechuic acid $49 \%$ BGR (MO, RP). This was followed by kaempferol 51\% BGR (MO, OS), caffeic acid $59 \%$ BGR (MO, OS), epicatechins 58\% BGR (RP, MO), gallic acid 63\% BGR (RP) ( $\uparrow$ with concentration), and rutin 77\% BGR (RP), as presented in Table 3.

According to Table 2, RP had the following polyphenols with antimicrobial activity on E. coli: protocatechuic acid, epicatechins, quercetin, and rutin. OS contained caffeic acid, kaempferol, and quercetin with an inhibitory effect on E. coli.

Macé et al. (2017) [53] used the microdilution method to test the effectiveness of several polyphenolic compounds at a concentration of $100 \mu \mathrm{g} \mathrm{mL}-1$ on S. pyogenes. They found that resveratrol was the most active from the list of standards that we tested. Meanwhile, epicatechin, quercetin, gallic acid, and ferulic acid were used only in the preliminary tests, and they proved no interfering effect on bacterial growth. Abachi et al. (2015) [54] also proved the inhibitory effect of epicatechin on S. pyogenes.

Bouarab-Chibane et al. (2019) [55] proved the antimicrobial effect of caffeic acid, rutin, epicatechin, and resveratrol against the tested P. aeruginosa, while, in their study, quercetin showed no effect. The researchers explained the mechanisms of antibacterial action of phenolic compounds at the cellular level, involving the modification in permeability of the cell membranes, the changes in various intracellular functions induced by hydrogen bonding of the phenolic compounds to enzymes, or by the modification of the cell wall rigidity with integrity losses due to different interactions with the cell membrane [55-58]. These processes induce irreversible damage of the cytoplasmic membrane, phenolic acids responsible for the disruption of the membrane integrity, causing leakage of the essential intracellular constituents. In the case of Gram-positive bacteria, intracellular $\mathrm{pH}$ modification and interference with the energy (ATP) were reported [54,59-61].

Marinas et al. (2014) [29], in their experiments, showed that alcoholic acacia extracts have antimicrobial activity against both Candida, Gram-positive bacteria (S. aureus, Bacillus subtilis, and Enterococcus faecalis) and Gram-negative (P. aeruginosa, E. coli, Klebsiella pneumoniae, and Acinetobacter baumannii).

Talas Ogras et al. (2005) [62] studied the in vitro antibacterial activity of the extract from $R$. pseudoacacia seeds, noting that $S$. aureus showed the highest sensitivity to the action of the extract.

According to the literature, it has been observed that several researchers have confirmed the antimicrobial activity of M. officinalis. Aćamović-Đoković et al. (2002) [63] compared the activity of M. albus (white sulphine), M. melissophyllum, and M. officinalis (yellow sulphine). Their study tested the antibacterial activity of petrol ether and ethyl acetate extract using the disk diffusion method in relation to E. coli, P. mirabilis, Salmonella enteritidis, P. aeruginosa, Streptococcus-haemoliticus type A, S. aureus, and C. albicans. The MO was more efficient than M. albus extracts.

Karakas et al. (2012) [52] carried out comparative research on biological activities and examined 16 plants from Turkey, including $M$. officinalis, using the diffusimetric method. The antibacterial activity of the aqueous extract of $M$. officinalis showed an area of growth inhibition on the strain tested on P. aeruginosa of $22.5 \mathrm{~mm}$. Moreover, methanol and ethyl acetate extracts from $M$. officinalis proved an inhibitory effect on fungi.

The antifungal activity of various M. officinalis extracts was tested on 12 pathogenic plant fungi in vitro and in vivo. The results showed that the antifungal activity of the ethyl acetate extract from M. officinalis was higher than the activity of the ethyl acetate extracts from other plants [64]. 
Studies on the effect of the ferulic and gallic acids on the mass growth of E. coli, $P$. aeruginosa, S. typhimurium, and L. monocytogenes were conducted by Borges et al. (2013) [60]. Protocatechuic acid showed an inhibitory effect on methicillin-resistant colonies of $S$. aureus, Klebsiella pneumonia, P. aeruginosa, and A. baumannii [65].

Resveratrol had an antibacterial effect against pathogenic bacteria in food: S. aureus, E. coli O157: H7, S. typhimurium, the action being more intense on Gram-positive than Gram-negative strains [66,67].

The literature structured on this topic proves the benefit of using natural products as microorganisms cannot acquire resistance to all biological compounds [68-72]. This becomes a new, viable option to fighting new and increasing strain resistance. Moreover, a great benefit of using natural products is the possible synergism or antagonism obtained due to the great diversity concerning the extract/oil content.

\section{Materials and Methods}

\subsection{Plant Material}

The aerial parts of the investigated medicinal plant species (MO, CV, OS, and RP) were collected during the flowering period from the wild flora located on the outskirts of Timisoara, Romania $\left(45^{\circ} 47^{\prime} 00.1^{\prime \prime} \mathrm{N}, 21^{\circ} 12^{\prime} 37.2^{\prime \prime} \mathrm{E}\right)$ in 2018 . From each species, $\sim 500 \mathrm{~g}$ of fresh material was used. Additionally, voucher specimens were botanically identified and deposited in a temperature-controlled herbarium $\left(22-25{ }^{\circ} \mathrm{C}\right.$ and $30-40 \%$ relative humidity) in the Botany Department, at the Banat University of Agricultural Sciences and Veterinary Medicine 'King Michael I of Romania' in Timişoara (Vouchers Specimen Number Herbarium-Botany Department, M.O-VSNH.BUASTM-BD56, C.V-VSNH.BUASTM-BD57, 0.S-VSNH.BUASTM-BD58, R.P-VSNH.BUASTM-BD59).

\subsection{Preparation of Extracts}

The plant material was air-dried at $25^{\circ} \mathrm{C}$ and ground to a fine powder using a grinder (GM 2000; Grindomix; Retsch Technology GMbH, Haan, Germany). The powdered material (2 g) was extracted with $20 \mathrm{~mL} \mathrm{60 \%} \mathrm{ethanol} \mathrm{(Sigma-Aldrich;} \mathrm{Merck} \mathrm{KGaA,} \mathrm{Darmstadt,}$ Germany) for $30 \mathrm{~min}$ at room temperature using an ultrasonic water bath (FALC Instruments, Treviglio, Italy) [73]. Extracts were then filtered using Whatman membrane filters nylon $0.45 \mu \mathrm{m}$ with $30 \mathrm{~mm}$ diameter (Sigma-Aldrich; Merck KGaA, Darmstadt, Germany) and stored at $2-4{ }^{\circ} \mathrm{C}$ for subsequent chemical and antimicrobial analyses [73].

\subsection{Determination of Total Polyphenols Content by Folin-Ciocalteu Assay}

The total phenolics content was determined according to Folin-Ciocalteu modified method [73]. An amount of $0.5 \mathrm{~mL}$ extract was treated with $1.25 \mathrm{~mL}$ Folin-Ciocalteu reagent (Sigma-Aldrich Chemie GmbH, München, Germany) diluted 1:10 with distilled water. The sample was incubated for $5 \mathrm{~min}$ at room temperature, then $1 \mathrm{~mL} \mathrm{Na}{ }_{2} \mathrm{CO}_{3}(\mathrm{Geyer} \mathrm{GmbH}$, Renningen, Germany) (60 g/L aqueous salts) was added. The samples were incubated for 30 min at $50^{\circ} \mathrm{C}$ in an INB500 thermostat, Memmert $\mathrm{GmbH}$, Schwabach, Germany) after reading absorbance at $750 \mathrm{~nm}$ using a UV-VIS spectrophotometer (Specord 205; Analytik Jena AG, Jena, Germany). As a reference, ethanol (Sigma-Aldrich; Merck KGaA, Darmstadt, Germany) was used. The calibration curve was obtained using gallic acid (concentration range: $2.5-250 \mu \mathrm{g} / \mathrm{mL}$ ). The results were expressed in mg GAE per g of dry matter (d.m.). All determinations were performed in triplicate.

\subsection{Determination of Individual Polyphenols by LC Analysis}

LC analysis was performed using a Shimadzu chromatograph (Shimadzu 2010 EV, Kyoto, Japan) equipped with an SPD-10A UV detector, EC 150/2 NUCLEODUR C18 Gravity SB $150 \times 2 \mathrm{~mm} \times 5 \mu \mathrm{m}$ column (Macherey-Nagel GmbH \& Co. KG, Dueren, Germany). The chromatographic system comprised an LC unit with a UV-VIS spectrophotometer detector (SPD-10A), a degasser, an autosampler, and solvent delivery pumps (LC-10AD). Chromatographic conditions were as follows. Mobile phases A: water acidified 
with formic acid (Merck KGaA, Darmstadt, Germany) at pH-3, and B: acetonitrile (Merck KGaA, Darmstadt, Germany) acidified with formic acid at $\mathrm{pH}-3$. The gradient program was $0.01-20 \min 5 \%$ B, 20.01-50 $\min 5-40 \%$ B , 5-55 min $40-95 \%$ B, 55-60 $\min 95 \%$ B. Solvent flow rate of $0.2 \mathrm{~mL} / \mathrm{min}$, temperature $200{ }^{\circ} \mathrm{C}$. The monitoring wavelength was $280 \mathrm{~nm}$ and $320 \mathrm{~nm}$. The calibration curves were performed in the range of $20-50 \mu \mathrm{g} / \mathrm{mL}$. The calibration curves were produced in the range of $1-10 \mu \mathrm{g} / \mathrm{mL}$. The results were expressed in $\mathrm{mg} \cdot \mathrm{g}^{-1} \mathrm{~d} . \mathrm{m}$. The experiments were performed in triplicate. All standards were prepared in methanol (Merck KGaA, Darmstadt, Germany) and all reagents and solvents used were analytical grade chemicals. Standards were purchased from Sigma-Aldrich, Merck KGaA, Darmstadt, Germany.

\subsection{Antimicrobial Activity}

The extracts were tested against S. aureus (ATCC 25923), S. pyogenes (ATCC 19615), E. coli (ATCC 25922), P. aeruginosa (ATCC 27853), S. flexneri (ATCC 12022), S. typhimurium (ATCC 14028), H. influenzae type B (ATCC 10211), C. albicans (ATCC 10231), and C. parapsilopsis (ATCC 22019).

The microorganisms used in this study were obtained from the culture collection of the Laboratory of Microbiology in the Interdisciplinary Research Platform within Banat's "King Michael I of Romania" the University of Agricultural Science and Veterinary Medicine Timisoara. In our laboratory, the ATCC strains were maintained at $-50{ }^{\circ} \mathrm{C}$.

McFarland standards were used to approximate the concentration of cells in a suspension visually. The McFarland scale is $\mathrm{CFU} / \mathrm{mL}$ specific concentrations and is designed to be used to estimate bacterial concentrations [74].

\subsubsection{Bacterial Culture}

A $10^{-3}$ dilution of the fresh culture was used to perform the assay, an inoculum equivalent to a $0.5 \mathrm{McF}$ arland standard. The ATCC microorganisms were revived by overnight growth in Brain Heart Infusion (BHI) broth (Oxoid, CM1135), at $37^{\circ} \mathrm{C}$, and subsequently, passed on BHI Agar (Oxoid, CM1136), for $24 \mathrm{~h}$ at $37^{\circ} \mathrm{C}$. The cultures were then diluted at an optical density (OD) of 0.5 McFarland standard $\left(1.5 \times 10^{8} \mathrm{UFC} \times \mathrm{mL}\right)$ using BHI broth. The suspensions were tested using a 96 microdilution well plate. Using a Calibra digital 852 multichannel pipette, $100 \mu \mathrm{L}$ of microbial suspension was placed in each well. The extracts were used directly, placing either 25,50 , or $100 \mu \mathrm{L}$ in each well. The plates were covered and left $24 \mathrm{~h}$ at $37^{\circ} \mathrm{C}$. After $24 \mathrm{~h}$, the OD was measured at $540 \mathrm{~nm}$ using an ELISA reader (BIORAD PR 1100, Hercules, CA, USA). Triplicate tests were performed for all samples. A mixture of $60 \%$ alcohol (according to the procedure used in the preparation of extracts) was tested for an inhibitory effect. The results proved no effect on the tested strains; therefore, the results were not presented here. The suspensions of strain and BHI were used as a negative control.

The MIC is defined as the lowest compound concentration that yields no visible microorganism growth. The method of MIC determination based on the microbial mass loss by measurement of OD by spectrophotometry according to ISO 20776-1:2019 was described in our previous research [73]. To interpret the results, two indicators were calculated, BGR and BIR, using the following formulas:

$$
\begin{gathered}
\mathrm{BGR}=\frac{\mathrm{OD}_{\text {sample }}}{\mathrm{OD}_{\text {negative }} \text { control }} \times 100 \quad(\%) \\
\mathrm{BIR}=100-\mathrm{BGR}(\%)
\end{gathered}
$$

where: OD sample - optical density at $540 \mathrm{~nm}$ as a mean value of triplicate readings for extracts and standards in the presence of the selected bacteria; OD negative control—optical density at $540 \mathrm{~nm}$ as a mean value of triplicate readings for the selected bacteria in BHI.

Concerning the standards tested, the method used was identical to the one used for the extract analysis. The quantities tested were calculated as the minimum and maximum 
amount of standard contained in the extracts within the same amount of extract tested, being 50 and $500 \mathrm{mg} \cdot \mathrm{g}^{-1}$.

\subsubsection{Fungi Culture}

A $10^{-2}$ dilution of the fresh culture was used to perform the assay, an inoculum equivalent to a $0.5 \mathrm{McF}$ arland standard. The ATCC microorganisms were revived by overnight growth in brain heart infusion (BHI) broth (Oxoid, CM1135), at $37{ }^{\circ} \mathrm{C}$, and subsequently, passed on BHI Agar (Oxoid, CM1136), for $48 \mathrm{~h}$ at $37^{\circ} \mathrm{C}$. The cultures were then diluted at an OD of $0.5 \mathrm{McF}$ arland standard using $\mathrm{BHI}$ broth. The suspensions were tested using a 96 microdilution well plate by placing $100 \mu \mathrm{L}$ of microbial suspension in each well. The extracts were used directly, placing 25,50 , or $100 \mu \mathrm{L}$ in each well. The plates were covered and left for $48 \mathrm{~h}$ at $37^{\circ} \mathrm{C}$. After $48 \mathrm{~h}$, the OD was measured at $540 \mathrm{~nm}$. Triplicate tests were performed for all samples.

To interpret the results, two indicators have been calculated, MGR and MIR, using the following formulas:

$$
\begin{gathered}
\text { MGR }=\frac{\mathrm{OD}_{\text {sample }}}{\mathrm{OD}_{\text {negative }} \text { control }} \times 100 \quad(\%) \\
\text { MIR }=100-\operatorname{MGR}(\%)
\end{gathered}
$$

where: OD sample-optical density at $540 \mathrm{~nm}$ as a mean value of triplicate readings for extracts and standards in the presence of the selected fungi; OD negative control—optical density at $540 \mathrm{~nm}$ as a mean value of triplicate readings for the selected fungi in BHI.

\subsection{Statistical Analysis}

All determinations were made in triplicate, and the results were reported as mean values \pm standard deviation (SD).

For total and individual polyphenols content, all replicates' mean values and standard deviations were calculated using GraphPad Prism (v.5.0 software, Manufacture, San Diego, CA, USA). The differences between means were analyzed with a one-way ANOVA, followed by a multiple comparison analysis using the $t$-test (two-sample assuming equal variances). The differences were considered significant when $p$-values $<0.05$. Correlations between variables were performed using Microsoft Excel 2010.

\section{Conclusions}

The study conducted on the antimicrobial potential of plant extracts belonging to the Fabaceae family pointed out that they can be considered promising antimicrobial agents. They open a new pathway for further research to find new complementary antibiotics against Gram-positive and/or negative bacteria and antifungal agents. The most sensitive tested plant extracts proved to be CV and RP against S. pyogenes, respectively, and MO against $P$. aeruginosa. In terms of chemical compounds responsible for the antimicrobial effect, kaempferol, quercetin, epicatechin, rutin, and protocatechuic acid showed appreciable inhibitory effects.

Supplementary Materials: The following are available online at https:/ / www.mdpi.com/article/10 $.3390 /$ antibiotics10060662/s1, Table S1: The OD mean values of extracts at $540 \mathrm{~nm}$.

Author Contributions: Conceptualization: D.O., I.C., E.A.; Methodology: D.O., A.C., M.N., A.L.C., and E.A.; Formal analysis: D.O., A.C., E.T., V.H., M.N., A.-G.N., I.N.; Original Draft Preparation: D.O., I.C., E.A., A.C., A.H.; Writing-Review \& Editing, D.O., I.C., E.A., A.C., A.H., I.R.; Visualization: D.O., I.C., E.T., V.H., M.N., A.C., A.-G.N., A.L.C., I.N., A.H., I.R., E.A.; Supervision: E.T., V.H., I.R.; funding acquisition, I.R. All authors have read and agreed to the published version of the manuscript.

Funding: This paper is published from own funds of the Banat University of Agricultural Sciences and Veterinary Medicine from Timisoara. 
Data Availability Statement: The report of the analyzes performed for the samples in the paper can be found at the Interdisciplinary Research Platform (PCI) belonging to the Banat University of Agricultural Sciences and Veterinary Medicine "King Michael I of Romania" from Timisoara, being registered with number 39c/29.05.2019.

Acknowledgments: We have been able to carry out this research with the support of the Interdisciplinary Research Platform belonging to Banat University of Agricultural Sciences and Veterinary Medicine "King Michael I of Romania" from Timisoara, where the chemical, antifungal, and herbicidal experiments were made.

Conflicts of Interest: The authors declare no conflict of interest.

\section{References}

1. Available online: https://www.who.int/news-room/detail/17-01-2020-lack-of-new-antibiotics-threatens-global-efforts-tocontain-drug-resistant-infections (accessed on 21 June 2020).

2. Sutjaritjai, N.; Wangpakapattanawong, P.; Balslev, H.; Inta, A. Traditional Uses of Leguminosae among the Karen in Thailand. Plants 2019, 8, 600. [CrossRef] [PubMed]

3. USDA-ARS. Germplasm Resources Information Network (GRIN); Online Database; National Germplasm Resources Laboratory; United States Department of Agriculture Agricultural Research Service: Beltsville, MD, USA, 2016.

4. Menković, N.; Šavikin, K.; Tasić, S.; Zdunić, G.; Stešević, D.; Milosavljević, S.; Vincek, D. Ethnobotanical study on traditional uses of wild medicinal plants in Prokletije Mountains (Montenegro). J. Ethnopharmacol. 2011, 133, 97-107. [CrossRef] [PubMed]

5. Grigorescu, E.; Ciulei, I.; Stanescu, U. Phytoterapic Index; Medicala: Bucuresti, Romania, 1986.

6. Zhao, G.C.; Yuan, Y.L.; Chai, F.R.; Ji, F.J. Effect of Melilotus officinalis extract on the apoptosis of brain tissues by altering cerebral thrombosis and inflammatory mediators in acute cerebral ischemia. Biomed Pharm. 2017, 89, 1346-1352. [CrossRef] [PubMed]

7. Al-Snafi, A.E. Therapeutic properties of medicinal plants: A review of their antibacterial activity (part 1). Int. J. Pharmacol. Toxicol. 2015, 6, 137-158.

8. Safapour, A.R.; Kaviyani, F.; Sepehrimanesh, M.; Ahmadi, N.; Hosseinabadi, O.K.; Tanideh, N.; Showraki, N. Antioxidant and anti-Inflammatory effects of gel and aqueous extract of Melilotus officinalis L. in induced ulcerative colitis: A Rattus norvegicus model. Ann. Colorectal. Res. 2015, 3, e29511.

9. Mladenović, K.; Grujović, M.; Stefanovic, O.; Vasić, S.; Čomić, L. Antimicrobial, antioxidant and antibiofilm activity of extracts of Melilotus officinalis (L.) pall. J. Anim. Plant Sci. 2016, 26, 436-1444.

10. Dušková, J.; Sovová, M.; Žáčková, P.; Spurná, V. Tissue culture of crownvetch (Coronilla varia L.) and the production of cardenolidelike substances in vitro. Biol. Plant. 1987, 29, 258-264. [CrossRef]

11. Dehpour, A.A. Chemical composition of essential oil and in vitro antibacterial and anticancer activity of the hydroalcolic extract from Coronilla varia. J. Nutr. Food Sci. 2016, 6, 52. [CrossRef]

12. Ţîței, V.; Teleuţă, A.; Coşman, V.; Coşman, S. Some biological features and biochemical composition of Crown Vetch (Coronilla Varia L.) in Moldova. Agron. Ser. Sci. Res. 2016, 59, 261-266.

13. Usta, C.; Yildirim, A.; Turker, A. Antibacterial and antitumour activities of some plants grown in Turkey. Biotechnol. Biotechnol. Equip. 2014, 28, 306-315. [CrossRef]

14. Baldemir, A.; Köroğlu, A.; Altanlar, N.; Coşkun, M. A comparative study on the in vitro antioxidant and antimicrobial potentials of three endemic Ononis L. species from Turkey. Turk. J. Pharm. Sci. 2018, 15, 125-129. [CrossRef]

15. Ferrante, C.; Chiavaroli, A.; Angelini, P.; Venanzoni, R.; Angeles Flores, G.; Brunetti, L.; Petrucci, M.; Politi, M.; Menghini, L.; Leone, S.; et al. Phenolic content and antimicrobial and anti-inflammatory effects of Solidago virga-aurea, Phyllanthus niruri, Epilobium angustifolium, Peumus boldus, and Ononis spinosa extracts. Antibiotics 2020, 9, 783. [CrossRef] [PubMed]

16. Deliorman Orhan, D.; Özçelik, B.; Hoşbaş, S.; Vural, M. Assessment of antioxidant, antibacterial, antimycobacterial, and antifungal activities of some plants used as folk remedies in Turkey against dermatophytes and yeast-like fungi. Turk. J. Biol. 2012, 36, 672-686. [CrossRef]

17. Dénes, T.; Bartha, S.G.; Kerényi, M.; Varga, E.; Balázs, V.L.; Csepregi, R.; Papp, N. Histological and antimicrobial study of Ononis Arvensis L. Biol. Futur. 2017, 68, 321-333. [CrossRef] [PubMed]

18. Forni, C.; Facchiano, F.; Bartoli, M.; Pieretti, S.; Facchiano, A.; D'Arcangelo, D.; Norelli, S.; Valle, G.; Nisini, R.; Beninati, S.; et al. Beneficial role of phytochemicals on oxidative stress and age-related diseases. Biomed Res. Int. 2019, 8748253. [CrossRef]

19. Anwer, M.S.; Mohtasheem, M.; Azhar, I.; Ahmed, S.W.; Bano, H. Chemical constituents from Melilotus officinalis. J. Basic Appl. Sci. 2008, 4, 89-94.

20. Patra, J.K.; Kim, E.S.; Oh, K.; Kim, H.-J.; Dhakal, R.; Kim, Y.; Baek, K.-H. Bactericidal effect of extracts and metabolites of Robinia pseudoacacia L. on Streptococcus mutans and Porphyromonas gingivalis causing dental plaque and periodontal inflammatory diseases. Molecules 2015, 20, 6128-6139. [CrossRef]

21. Xu, D.P.; Li, Y.; Meng, X.; Zhou, T.; Zhou, Y.; Zheng, J.; Zhang, J.J.; Li, H.B. Natural Antioxidants in Foods and Medicinal Plants: Extraction, Assessment and Resources. Int. J. Mol. Sci. 2017, 18, 96. [CrossRef] [PubMed]

22. Veitch, N.C.; Elliott, P.C.; Kite, G.C.; Lewis, G.P. Flavonoid glycosides of the black locust tree, Robinia pseudoacacia (Leguminosae). Phytochemistry 2010, 71, 479-486. [CrossRef] 
23. Tian, F.; Chang, C.J.; Grutzner, J.B.; Nicholsa, D.E.; McLaughlin, J.L. Robinlin: A novel bioactive homo-monoterpene from Robinia pseudoacacia L. (Fabaceae). Bioorganic Med. Chem. Lett. 2001, 11, 2603-2606. [CrossRef]

24. Herman, V.; Rosiu, D.; Catana, N.; Degi, J.; Iancu, I.; Mititi, I.; Ciobanu, G.; Grema, C.F.; Pascu, C. Evaluation of propolis for antibacterial activity in vitro. Rev. Rom. Med. Vet. 2018, 28, 13-17.

25. Lobo, V.; Patil, A.; Phatak, A.; Chandra, N. Free radicals, antioxidants and functional foods: Impact on human health. Pharmacogn. Rev. 2010, 4, 118-126. [CrossRef] [PubMed]

26. Alexa, E.; Danciu, C.; Radulov, I.; Obistioiu, D.; Sumalan, R.M.; Morar, A.; Dehelean, C.A. Phytochemical Screening and Biological Activity of Mentha $\times$ piperita L. and Lavandula angustifolia Mill. Extracts. Anal. Cell. Pathol. 2018. [CrossRef] [PubMed]

27. Obistioiu, D.; Cristina, R.T.; Schmerold, I.; Chizzola, R.; Stolze, K.; Nichita, I.; Chiurciu, V. Chemical characterization by GCMS and in vitro activity against Candida albicans of volatile fractions prepared from Artemisia dracunculus, Artemisia abrotanum, Artemisia absinthium and Artemisia vulgaris. Chem. Cent. J. 2014, 8. [CrossRef]

28. Gordon, M.H. The mechanism of antioxidant action in vitro. In Food Antioxidants; Hudson, B.J.F., Ed.; Elsevier Science Publishing: New York, NY, USA, 1990; pp. 1-18.

29. Marinas, I.; Oprea, E.; Geana, I.; Chifiriuc, M.; Lazar, V. Antimicrobial and antioxidant activity of the vegetative and reproductive organs of Robinia pseudoacacia. J. Serbian Chem. Soc. 2014, 79, 49. [CrossRef]

30. Stefanović, O.D.; Tešić, J.D.; Čomić, L.R. Melilotus albus and Dorycnium herbaceum extracts as source of phenolic compounds and their antimicrobial, antibiofilm, and antioxidant potentials. J. Food Drug Anal. 2015, 23, 417-424. [CrossRef]

31. Stankov, S.; Fidan, H.; Ivanova, T.; Stoyanova, A.; Damyanova, S.; Desyk, M. Chemical composition and application of flowers of false acacia (Robinia pseudoacacia L.). Ukr. Food J. 2018, 7, 577-588. [CrossRef]

32. Arnold, E.; Benz, T.; Zapp, C.; Wink, M. Inhibition of cytosolic phospholipase A2 $\alpha$ (cPLA2 $\alpha$ ) by medicinal plants in relation to their phenolic content. Molecules 2015, 20, 15033-15048. [CrossRef]

33. Liu, Y.T.; Gong, P.H.; Xiao, F.Q.; Shao, S.; Zhao, D.Q.; Yan, M.M.; Yang, X.W. Chemical constituents and antioxidant, antiinflammatory and anti-tumor activities of Melilotus officinalis (Linn.) Pall. Molecules 2018, 23, 271. [CrossRef]

34. Tang, C.N. Study on the extraction process of total flavonoids from Melilotus officinalis medicinal plant. J. Anhui. Agric. Sci. 2012, 3, 23-25. [CrossRef]

35. Yang, J.; Wang, L.L.; Zhang, T.J. Research progress on chemical constituents in plants of Melilotus Linn. and their pharmacological activities. Chin. Tradit. Herb. Drugs 2014, 45, 447-454.

36. Pleşca-Manea, L.; Pârvu, A.E.; Pârvu, M.; Tămaş, M.; Buia, R.; Puia, M. Effects of Melilotus officinalis on acute inflammation. Phytother. Res. 2002, 16, 316-319. [CrossRef] [PubMed]

37. Yan, M.M.; Wu, C.Y.; Wei, Z.X.; Fu, M.L.; Liu, C.; Tian, S.; Shao, S. Anti-cancer effect of external saponins from Melilotus officinalis L. Jilin J. Tradit. Chin. Med. 2015, 35, 191-192.

38. Yan, M.M.; Yang, Z.; Wang, Y.S.; Zhao, D.Q.; Wu, Y.; Zhang, Y.L.; Yu, H.W.; Zhou, Y. The preparation method and drug use of total saponin from Melilotus officinalis. CN Patent CN102178725 A, 14 September 2011.

39. Dombrowicz, E.; Swiatek, L.; Guryn, R.; Zadernowski, R. Phenolic acids in herb Melilotus officinalis. Pharmazie 1991, 46, 156-157.

40. Molnar, M.; Jerković, I.; Suknović, D.; Bilić Rajs, B.; Aladić, K.; Šubarić, D.; Jokić, S. Screening of six medicinal plant extracts obtained by two conventional methods and supercritical $\mathrm{CO}_{2}$ extraction targeted on coumarin content, 2,2-Diphenyl-1picrylhydrazyl radical scavenging capacity and total phenols content. Molecules 2017, 22, 348. [CrossRef]

41. Al-Snafi, A. Chemical constituents and pharmacological effects of Melilotus officinalis-A review. IOSR J. Pharm. 2020, 10, 26-36.

42. Jasicka-Misiak, I.; Makowicz, E.; Stanek, N. Polish yellow sweet clover (Melilotus officinalis L.) honey, chromatographic fingerprints, and chemical markers. Molecules 2017, 22, 138. [CrossRef]

43. Călina, D.; Olah, N.K.; Pătru, E.; Docea, A.; Popescu, H.; Bubulica, M.V. Chromatographic analysis of the flavonoids from Robinia pseudoacacia species. Curr. Health Sci. J. 2013, 39, 232-236.

44. Li, Y.; Chu, Z.; Zhai, Y.; Kang, T. Preparation technique of total flavone of Robinia psendoacacia. J. Liaoning Univ. 2011, 13, 87-88.

45. Wang, X.; Tang, L.; Zhao, L.; Luan, Y.; Zhang, Z. Determination of polyphenols in flowers of R. pseudoacacia L. by Folin-ciocaileu method. J. Food Drug 2010, 12, 332-334.

46. Wang, X.; Tang, L.; Zhao, L. Optimization of ultrasound-assisted extraction of phenolic compounds from R. pseudoacacia L. flowers by response surface methodology. J. Food Sci. 2011, 32, 66-40.

47. Alanon, M.; Castro, L.; Hidalgo, M.C.; Hermosín-Gutiérrez, I.; Gordon, M.; Pérez-Coello, M.S. Antioxidant capacity and phenolic composition of different woods used in cooperage. Food Chem. 2011, 129, 1584-1590. [CrossRef]

48. Ferrante, C.; Angelini, P.; Venanzoni, R.; Angeles Flores, G.; Tirillini, B.; Recinella, L.; Chiavaroli, A.; Brunetti, L.; Leone, S.; Di Simone, S.C.; et al. Antimicrobial, antioxidant, and antiproliferative effects of Coronilla minima: An Unexplored Botanical Species. Antibiotics 2020, 9, 611. [CrossRef] [PubMed]

49. Rosu, A.; Bita, A.; Calina, D.; Rosu, L.; Zlatian, O.; Calina, V. Synergic antifungal and antibacterial activity of alcoholic extract of the species Robinia pseudoacacia L. (Fabaceae). Eur. J. Hosp. Pharm. 2012, 19, 216. [CrossRef]

50. Sisay, M.; Bussa, N.; Gashaw, T.; Mengistu, G. Investigating in vitro antibacterial activities of medicinal plants having folkloric repute in Ethiopian traditional medicine. J. Evid. Based Integr. Med. 2019, 24, 2515690X19886276. [CrossRef]

51. Morar, A.; Sala, C.; Imre, K. Occurrence and antimicrobial susceptibility of Salmonella isolates recovered from the pig slaughter process in Romania. J. Infect. Dev. Ctries. 2015, 9, 99-104. [CrossRef] 
52. Karakas, F.P.; Yildirim, A.; Turker, A. Biological screening of various medicinal plant extracts for antibacterial and antitumor activities. Turk. J. Biol. 2012, 36, 641-652. [CrossRef]

53. Macé, S.; Truelstrup Hansen, L.; Rupasinghe, H.P.V. Anti-bacterial activity of phenolic compounds against Streptococcus pyogenes. Medicines 2017, 1, 25. [CrossRef] [PubMed]

54. Abachi, S.; Lee, S.; Rupasinghe, H.P. Molecular mechanisms of inhibition of Streptococcus species by phytochemicals. Molecules 2016, 17, 215. [CrossRef]

55. Bouarab-Chibane, L.; Forquet, V.; Lantéri, P.; Clément, Y.; Léonard-Akkari, L.; Oulahal, N.; Degraeve, P.; Bordes, C. Antibacterial properties of polyphenols: Characterization and QSAR (Quantitative Structure-Activity Relationship) models. Front. Microbiol. 2019, 10, 829. [CrossRef]

56. Ikigai, H.; Nakae, T.; Hara, Y.; Shimamura, T. Bactericidal catechins damage the lipid bilayer. Biochim. Biophys. Acta Biomembr. 1993, 1147, 132-136. [CrossRef]

57. Stapleton, P.D.; Shah, S.; Hamilton-Miller, J.M.T. Anti-Staphylococcus aureus activity and oxacillin resistance modulating capacity of 3- O-acylcatechins. Int. J. Antimicrob. Agents 2004, 24, 374-380. [CrossRef] [PubMed]

58. Taguri, T.; Tanaka, T.; Kouno, I. Antibacterial spectrum of plant polyphenols and extracts depending upon hydroxyphenyl structure. Biol. Pharm. Bull. 2006, 29, 2226-2235. [CrossRef]

59. Cushnie, T.T.; Lamb, A.J. Recent advances in understanding the antibacterial properties of flavonoids. Int. J. Antimicrob. Agents 2011, 38, 99-107. [CrossRef] [PubMed]

60. Borges, A.; Ferreira, C.; Saavedra, M.J. Antibacterial activity and mode of action of ferulic and gallic acids against pathogenic bacteria. Microb. Drug Resist. 2013, 19, 256-265. [CrossRef]

61. Imre, K.; Herman, V.; Morar, A. Scientific Achievements in the Study of the Occurrence and Antimicrobial Susceptibility Profile of Major Foodborne Pathogenic Bacteria in Foods and Food Processing Environments in Romania: Review of the Last Decade. BioMed Res. Int. 2020, e5134764. [CrossRef]

62. Talas-Oğraş, T.; Ipekçi, Z.; Bajroviç, K.; Gözükirmizi, N. Antibacterial activity of seed proteins of Robinia pseudoacacia. Fitoterapia 2005, 76, 67-72. [CrossRef]

63. Aćamović-Đoković, G.; Đukić, D.; Mandić, L.; Kalinić, S.; Bošković, T. Antimicrobial activity of the petrol-ether and ethyl-acetate extracts of Melilotus officinalis (L.) Pall, Melilotus albus medic. and Melitis melissophyllum L. Lek. Sirovine 2002, 22, 59-63.

64. Stefanovic, O.; Čomić, L. Synergistic antibacterial interaction between Melissa officinalis extracts and antibiotics. J. Appl. Pharm. Sci. 2012, 2, 1-5.

65. Miklasińska, M.; Kępa, M.; Wojtyczka, R.D.; Idzik, D.; Zdebik, A.; Orlewska, K.; Wąsik, T.J. Antibacterial activity of protocatechuic acid ethyl ester on Staphylococcus aureus clinical strains alone and in combination with antistaphylococcal drugs. Molecules 2015, 20, 13536-13549. [CrossRef]

66. Ma, D.; Tan, L.T.; Chan, K.G.; Yap, W.H.; Pusparajah, P.; Chuah, L.H.; Ming, L.C.; Khan, T.M.; Lee, L.H.; Goh, B.H. Resveratrolpotential antibacterial agent against foodborne pathogens. Front. Pharmacol. 2018, 9, 102. [CrossRef]

67. Tîrziu, E.; Bărbălan, G.; Morar, A.; Herman, V.; Cristina, R.T.; Imre, K. Occurrence and antimicrobial susceptibility profile of Salmonella spp. in raw and ready-to-eat foods and Campylobacter spp. in retail raw chicken meat in Transylvania, Romania. Foodborne Pathog. Dis. 2020, 17, 479-484. [CrossRef]

68. Renda, G.; Özel, A.; Barut, B.; Korkmaz, B.; Yaylı, N. The volatile chemical compositions of the essential oil/SPME and enzyme inhibitory and radical scavenging activities of solvent extracts and the essential oils from Coronilla orientalis Miller and C. varia $\mathrm{L}$. grows in Turkey. Iran. J. Pharm. Res. 2019, 18, 1831-1842. [CrossRef] [PubMed]

69. Martínez-Gil, A.; del Alamo-Sanza, M.; Sánchez-Gómez, R.; Nevares, I. Alternative woods in enology: Characterization of tannin and low molecular weight phenol compounds with respect to traditional oak woods. A Review. Molecules 2020, 25, 1474. [CrossRef]

70. Stojković, D.; Dias, M.I.; Drakulić, D.; Barros, L.; Stevanović, M.; Ferreira, I.C.F.R.; Soković, M.D. Methanolic extract of the herb Ononis spinosa L. is an antifungal agent with no cytotoxicity to primary human cells. Pharmaceuticals 2020, 13, 78. [CrossRef] [PubMed]

71. Beteg, F.; Vieilly, V.; Fit, N.; Muresan, C.; Gal, A.; Stancu, B.; Pascu, C.; Herman, V. Propolis-an ancient remedy or a new paradigm for wound healing: In-vivo preclinical evaluation, antimicrobial activity and histopathologic aspects. Rev. Rom. Med. Vet. 2019, 29, 12-17.

72. WHO. European Health Report 2018: More than Numbers-Evidence for All; ii + 16 pages; WHO: Copenhagen, Denmark, 2018; ISBN 9789289053440.

73. Cocan, I.; Alexa, E.; Danciu, C.; Radulov, I.; Galuscan, A.; Obistioiu, D.; Morvay, A.A.; Sumalan, R.M.; Poiana, M.A.; Pop, G.; et al. Phytochemical screening and biological activity of Lamiaceae family plant extracts. Exp. Ther. Med. 2018, 15, 1863-1870. [CrossRef] [PubMed]

74. Alexa, V.T.; Galuscan, A.; Popescu, I.; Tirziu, E.; Obistioiu, D.; Floare, A.D.; Perdiou, A.; Jumanca, D. Synergistic/ Antagonistic Potential of Natural Preparations Based on Essential Oils Against Streptococcus mutans from the Oral Cavity. Molecules 2019, 24, 4043. [CrossRef] [PubMed] 